This item was submitted to Loughborough's Research Repository by the author.

Items in Figshare are protected by copyright, with all rights reserved, unless otherwise indicated.

\title{
Do commodities make effective hedges for equity investors?
}

PLEASE CITE THE PUBLISHED VERSION

https://doi.org/10.1016/j.ribaf.2017.07.064

PUBLISHER

(c) Elsevier

VERSION

AM (Accepted Manuscript)

PUBLISHER STATEMENT

This work is made available according to the conditions of the Creative Commons Attribution-NonCommercialNoDerivatives 4.0 International (CC BY-NC-ND 4.0) licence. Full details of this licence are available at: https://creativecommons.org/licenses/by-nc-nd/4.0/

\section{LICENCE}

CC BY-NC-ND 4.0

\section{REPOSITORY RECORD}

Olson, Eric, Andrew Vivian, and Mark Wohar. 2019. "Do Commodities Make Effective Hedges for Equity Investors?". figshare. https://hdl.handle.net/2134/25836. 
Do Commodities Make Effective Hedges for Equity Investors?

\author{
Eric Olson \\ West Virginia University, USA \\ Eric.olson@mail.wvu.edu \\ Andrew Vivian \\ Loughborough University, UK \\ a.j.vivian@lboro.ac.uk \\ Mark E. Wohar \\ University of Nebraska-Omaha, USA \\ mwohar@mail.unomaha.edu \\ and \\ Loughborough University, UK
}

January, 2017

Key words: Dynamic Hedge Ratios, Conditional Correlation, Commodity Market, Equity Index, Risk Management

JEL: C12, C32, G10 


\begin{abstract}
The purpose of this paper is to evaluate whether commodities are effective hedges for equity holders. We employ three different methodologies to calculate time varying hedge ratios. First, we examine time-varying hedge ratios and how much portfolio risk can be reduced relative to a long position in the S\&P 500. We calculate hedge ratios from realized variances and covariances; second, we estimate a recursive multivariate GARCH (BEKK) model and calculate the hedge ratios from the estimated covariances; and thirdly, we calculate the hedge ratios by estimating recursive OLS regressions. The results of our paper are very clear. First, commodities are not effective hedges for the S\&P 500. Equity market investors and asset managers looking for a way to manage and reduce portfolio risk will be well advised to search for alternative hedges for the S\&P 500 than commodities. Second, our results do not support the claim that commodities were a good hedge for the equity market during the financial crisis.
\end{abstract}




\section{Introduction}

There is growing evidence that equity and commodity markets are inter-connected and that the correlations between commodities and equities have generally increased since the early 2000s (see for example Silvennoinen and Thorp, 2013; Creti, Joets, and Mignon, 2013; Gilbert, 2010); during which time commodities have been increasingly used by asset managers for diversification and traders for speculation. This process has been deemed “financialization”. While several studies have investigated whether the time series properties of commodity returns have changed since the early 2000s or been influenced by "financialization”, the results are mixed. ${ }^{1}$ Thus, the source of the rising correlation between energy commodities and equities may not be the "financialization" of commodities but rather may reflect other factors.

Prior literature appears to have largely overlooked the fact that increased correlations will actually make (short) commodities a better hedge for (long) equity (provided the absolute value of the correlation coefficient increases). Given that hedging typically involves taking a long position in one asset (here equity) and a short position in another asset (here a commodity futures), the rise in correlations (as noted in Tang and Xiong, 2012; Olson et al., 2014) suggests that a move in equity price will be better offset by a short position in the commodity; thus, the hedge should become more effective. Recent work documents average hedge ratios and reports the average cost of hedging the equity market using commodities (Sadorsky, 2014; Mensi et al., 2013); we extend this important line of research on crosshedging to examine in detail how effective a tool commodities are for portfolio managers wishing to hedge equity market fluctuations in real-time. Precisely how much of the variation of the equity index or downside risk can be reduced by implementing a commodity hedge? The use of commodities by portfolio managers and traders is certainly a crucial issue that

\footnotetext{
${ }^{1}$ For example Vivian and Wohar (2012) report that while there are breaks in commodity volatility since 2000 there is little evidence that they became more frequent compared to pre-2000 nor that the influx of more speculative investors that accompanied Financialization lead to a general increase in commodity return volatility.
} 
attracts attention from policymakers, producers, academics, investors, the media and consumers.

In the traditional hedging strategy, hedgers choose their futures market positions as equal magnitude but of opposite sign to their cash market positions (Ederington, 1979). Johnson (1960) and Stein (1961) unify traditional hedging theory with profit maximization to introduce minimumvariance hedging. The minimum-variance hedging strategy consists of choosing a futures position to minimize the variance of the hedged portfolio and is, by definition, the best strategy based upon within-sample hedging effectiveness comparisons (Kroner and Sultan, 1993). A large body of literature has emerged wherein econometric models are applied to estimate hedge ratios in order to examine which hedging method is preferred, for example, does a dynamic hedge strategy estimated via GARCH outperform a minimum-variance hedge strategy estimated via OLS. The minimumvariance hedge strategy is frequently adopted as a benchmark as researchers search for strategies that outperform the minimum-variance strategy.

The hedging effectiveness measure proposed by Ederington (1979) has been the most popular criterion to evaluate the usefulness of a hedge. Ederington (1979) proposes to measure the effectiveness of a futures hedging strategy by the percentage reduction in the variance of the hedged portfolio relative to the variance of the spot position. Different hedging strategies are compared in terms of Ederington's Hedging Effectiveness (EHE) measure, and the strategy having the greatest EHE is seen as the best strategy. ${ }^{2}$ The literature examines the conventional static OLS strategy and the Generalized Autoregressive Conditional Heteroskedasticity (GARCH) method of estimating conditional variance introduced by Bollerslev (1982). The traditional OLS hedge ratio is obtained by regressing the returns to holding the spot asset on the returns to holding the hedging instrument (i.e. the

\footnotetext{
2 The EHE measure is termed certainty equivalent and is derived from expected utility comparisons between hedged and unhedged portfolios. It can be shown that the sample certainty equivalent estimator, similar to the in-sample EHE estimator, is biased. This utility-based effectiveness measure does not necessarily favor the OLS hedge ratio except when the futures price is a martingale or when the hedger is extremely risk averse. While the variance can be conditional or unconditional, in empirical studies EHE is always calculated on the basis of unconditional variance as in Ederington (1979).
} 
futures return). The GARCH hedge ratio, obtained from the Autoregressive Conditional Heteroskedastic process introduced by Engle (1982), allows for past conditional variances to change over time as a function of past errors, while the unconditional variance remains constant.

Our aim in this paper is to provide a comprehensive evaluation of whether commodities are effective hedges for equity holders in real time and which estimation method is best. In this paper we examine time-varying hedge ratios and how much portfolio risk can be reduced (in real-time) relative to a long position in the S\&P 500. As such, we implement three different methodologies to calculate time varying hedge ratios. First, we calculate hedge ratios from realized variances and covariances. Our primary motivation for using realized volatilities in the calculations of the dynamic hedge ratios is to examine the degree to which the distributional assumptions embedded in multivariate GARCH and recursive OLS models markedly altered the dynamic hedge ratios. Second, we estimate a recursive multivariate GARCH (BEKK) model and calculate the hedge ratios from the estimated covariances; and thirdly, we calculate the hedge ratios by estimating recursive OLS regressions. Fourthly we take an average of all three individual hedge ratios. We then examine the time-series properties of the hedge ratios. Finally we provide extensive evidence on whether hedging with commodities can substantially reduce equity index portfolio variance or equity downside risk and whether this requires any sacrifice of portfolio return. While some prior work estimates average hedge ratios between commodities and an equity index (e.g. Sadorsky, 2014; Mensi et al., 2013), we extend this to examine directly how much risk can be reduced from implementing such cross-hedging strategies out-of-sample. We additionally investigate whether there is time-variation in the effectiveness of the hedges and also seek to shed light on how well a realized volatility (and covariance) based hedge ratio compares to GARCH or OLS based hedge ratios. 
The results of our paper are very clear. First, commodities are not effective hedges for the S\&P 500. This holds in general across all of the hedging methods that we consider. Hence, equity market investors and asset managers looking for a way to manage and reduce portfolio risk will be well advised to search for alternative hedges for the S\&P 500 than commodities. Second, while the correlation between commodities and S\&P 500 may have increased during the financial crisis period, we find that this was not sufficient to make commodities a good hedge for the equity market even during this period; while some models do slightly better over recent years they still are only able to hedge a small portion of portfolio risk. ${ }^{3}$

The remainder of this paper is organized as follows. Section 2 summarizes recent literature. Section 3 discusses our data and methodology. Section 4 presents our model results and evaluates time varying hedge ratios. Section 5 concludes.

\section{Literature Review}

There is a growing body of literature that examines if commodities are useful for diversification of an investment portfolio (see for example Jenson, Johnson and Mercer, 2000; Erb and Harvey, 2006; Gorton and Rouwenhorst, 2006). Jenson, Johnson and Mercer (2000) consider the mean-variance optimizing investor and find (s)he would place a substantial weight on commodities in a multi-asset portfolio comprising stocks, bonds, TBills and real estate; they find portfolio returns are increased when commodities are included, regardless of the level of risk. Jenson, Johnson and Mercer (2000) also highlight that the weight on commodities is higher during restrictive monetary policy conditions. Gorton and Rouwenhorst (2006) emphasise that commodities and equities fluctuate in different ways over the business cycle. Erb and Harvey (2006) report that correlations within the commodity

\footnotetext{
${ }^{3}$ It is the absolute correlation coefficient that is key in terms of determining hedging performance and hence if there was a dramatic fall (rather than a rise) in correlations then this should also improve hedging performance.
} 
market tend to be very low; hence they suggest an equally weighted portfolio of commodities can offer large diversification benefits. They also find there can be gains from momentum based strategies and from exploiting information in the term structure of commodities; these have been further substantiated by Fuertes, Miffre and Rallis (2010). Overall, Erb and Harvey (2006) suggest that a portfolio of commodities can offer return and risk characteristics similar to equities.

The use of various GARCH models for estimating hedge ratios has produced a large amount of financial literature to determine optimal hedging strategies and to measure the effectiveness of these policies. Kroner and Sultan (1993) point out that the conventional (OLS) hedge ratio (i.e. the ratio derived from regressing the spot return on the futures return) outperforms all other constant hedge ratio strategies for in-sample comparisons. Lien (2005a, b) extends the conclusion to out-of-sample comparisons. Lien (2005a, b) further suggested that the conventional hedging strategy also tends to outperform others in terms of post-sample hedging effectiveness, unless there is a structural change across the estimation sample. Lien (2006) demonstrates that the minimum-variance strategy likely dominates the GARCH hedge strategy as well. Lien, Lee, Yang, and Zhou (2014) examines the EHE comparisons between the OLS hedge strategy (i.e., the unconditional strategy) with various conditional hedge strategies, assuming spot and futures returns are described by different statistical framework. They show that for most statistical models, the OLS hedge strategy is likely to outperform the optimal conditional hedge strategy. ${ }^{4}$

The development of futures markets have provided scope for improving risk management through the implementation of dynamic hedging strategies, as opposed to static OLS hedging strategies, where the hedge ratio is re-adjusted with the arrival of new

${ }^{4}$ For example, in a vector error correction model (VECM), the optimal conditional hedge ratio should take into account the cointegrating relationship. The resulting EHE from this optimal ECM hedge ratio, however, underperforms the OLS hedge ratio (where the cointegration relationship is ignored). Similarly, when spot and futures returns follow a multivariate generalized autoregressive conditional heteroskedasticity (MGARCH) model, the GARCH hedge ratio is likely to be inferior to the OLS hedge ratio in terms of EHE. The risk reduction effect of the OLS hedge ratio may be overstated if it is compared using EHE with the effects of conditional hedge ratios. 
information into the market. GARCH models and their bivariate extension are the most widely used as they are able to reflect the main patterns of the spot and futures financial series, so they provide more effective hedging strategies (Myers, 1991; Kroner and Sultan, 1993; Park and Switzer. 1995). Baillie and Myers (1991) first derived hedge ratios using the bivariate GARCH model. Other versions of the GARCH models have been used in the finance literature. Kroner and Sultan (1993), for example, employ the Constant Conditional Correlation GARCH (CCC-GARCH) model in the foreign-exchange market, while Gagnon et al. (1998) expands the Kroner and Sultan study to multi-asset portfolios using the BEKK GARCH model. Haigh and Holt (2000, 2002) investigate hedging in the freight and crack spread markets using a modified BEKK GARCH model. Other research that employ the family of GARCH models for hedging include Lee and Yorder (2007a, 2007b), Lee (2009, 2010), Chang et al. (2011), and Ji and Fan (2011). All these papers conclude that a GARCH-based strategy is superior to other static hedges.

As Hill and Schneeweis (1982), Figlewski (1984), Herbst et al. (1989), and Fama (1965) find that asset covariance structures are time-varying, the GARCH method allows the conditional variance to change over time as a function of past errors (Bollerslev, 1982). Those that have found the GARCH hedge ratios to be superior argue that the implementation of GARCH is necessary in order to capture the time-varying asset covariance structure. This should allow GARCH-based minimum-variance hedging to provide greater variance reduction than naive hedging. However, as a result of uncertainty in the GARCH specification as well as in parameter estimates, this conclusion may not hold true in practice. Lamoureux and Lastrapes (1990) note that these models tend to overestimate volatility persistence due to the lack of consideration for sudden changes in the unconditional volatility. As these sudden changes are present in most financial series (Ewing and Malik, 2005; Aggarwal et al., 1999; Huang and Yang, 2001; Sanso et al., 2004), not considering them could have effects on the variance forecast and on the 
determination and effectiveness of optimal dynamic hedging strategies (Wilson et al., 1996). Many of the above mentioned studies conclude that econometric methods are able to improve hedging performance over the naive hedging strategy of shorting one futures contract per unit of spot exposure. However, the hedge ratios obtained from GARCH-type models are extremely volatile, suggesting unrealistically frequent re-balancing and hence very large transaction costs for the hedged portfolio.

Alexander, Prokopczuk, and Sumawong (2013) conduct an extensive out-of-sample study of minimum-variance hedging for a complex underlying position. They compare the empirical performance of the minimum-variance hedging strategy, comparing several econometric models for estimating hedge ratios for crude oil, gasoline and heating oil crack spreads. Several hedging approaches and covariance estimation techniques are compared with a simple naïve hedge, explicitly taking margin and transaction costs into account, which are not explicitly modelled in most previous work. They also evaluate the hedge performance based on profit and loss made. In contrast to the extant literature they find that there is no econometric method that can outperform the naïve hedge. Moreover, the existence of cointegration relationships between spot and futures markets leads Ghosh (1993) and Lien (1996) to the incorporation of an Error Correction Term (ECT) in the mean equation. Lien and Shrestha (2010) examine 24 commodity and financial futures markets to compare the hedging effectiveness of the minimum-variance strategy with that of the naïve hedge strategy and a hedge strategy generated from the error correction (EC) model. They find that when there is structural change, the naïve strategy outperforms both MV and EC hedge ratios. Wu, Guan and Myers (2011) examine cross-hedging in the context of corn and crude oil, while they find substantial spillovers between these commodities they find a limited role for oil as a crosshedge for corn. Our aim is to implement portfolio tests using hedge ratios from three common methodologies to examine the usefulness of commodities as hedging instruments. 


\section{DATA AND METHODOLOGY}

Our main empirical analysis is based upon monthly data taken from Thomson's Datastream. ${ }^{5}$ The sample period is from January $1^{\text {st }} 1985$ to July $31^{\text {st }} 2014$. This period covers the early 1990s global recession, the more recent financial crisis as well as periods of economic growth. The S\&P 500 spot index return is used to proxy the US equity market. We investigate several commodity excess return indices from Goldman Sachs; specifically we use the Energy index, the Industrial Metals index, the Precious Metals index, the Agriculture index and the Livestock index. This is based on a long-only investment in commodity futures and index components are capitalization weighted. Each index is a barometer for the whole of their sector and they are frequently used as benchmarks for investment performance.

To calculate the various hedge ratios we employ three methodologies: i) Realized Volatility, ii) Multivariate GARCH and iii) Recursive OLS. These are explained in turn.

\subsection{Realized Volatility}

First, we discuss the realized volatility based hedge ratio. As noted above, our motivation in using realized volatility measures is to relax the distributional assumptions embedded within multivariate GARCH and recursive OLS models. We believe this to be an important robustness check for multivariate GARCH models; especially, given the convergence problems associated with multivariate GARCH models due to the large number of parameters to be estimated. Many multivariate GARCH models impose restrictions on the covariance matrix to enable convergence; while we are not criticizing such models, our aim is simply to compare dynamic hedge ratios from such models with dynamic hedge ratios from realized volatility models (which impose no such restrictions) for robustness.

\footnotetext{
${ }^{5}$ Monthly data (averaged over 21 trading days) are implemented in the study for several reasons. Firstly, it enables us to estimate and evaluate effectively realized hedges based on 21 days of data without encountering issues with overlapping observations which would plague the time series tests we conduct. Secondly, lower frequency data substantially reduces any issues relating to non-synchronicity (different market closing times). Even in the US stock markets and commodity markets generally close at different times which would impact analysis on daily data and to an extent weekly data. Thirdly, it reduces the impact of trading costs incurred due to frequent rebalancing of the hedge on our hedge effectiveness analysis.
} 
There are concerns relating to overlapping observations in the realized volatility measures. This may generate non-stationary hedge ratios. In order to ensure this does not occur for the realized volatility measures we estimated these using a fixed number of observations in each time period, we set each time period equal to 21 trading days which is approximately one month. We then estimate subsequent methods, GARCH and recursive OLS using data cumulated over each trading period so that all methods can be appropriately compared.

To estimate the realized volatility hedge ratios we begin by estimating:

$$
\overline{\operatorname{Ret}}_{t}^{i}=\frac{1}{k-1} \sum_{j=1}^{k} \operatorname{Ret}_{j, t}^{i}
$$

where $\overline{\operatorname{Ret}}_{t}^{i}$ is the average return for commodity $i$ within each daily interval of time $t$. We set $k$ to be equal to the average number of trading days in a month (21). $\operatorname{Ret}_{j, t}^{i}$ is the volatility of commodity $i$ on the $j$ th day of period $t$. We implement the same approach as (1) for the S\&P 500 index as well.

We then use these return measures to calculate the (average) realized variances during period $t$ using:

$$
\operatorname{var}_{t}^{i}=\frac{1}{k-1} \sum_{j=1}^{k}\left(\operatorname{Ret}_{j, t}^{i}-\overline{\operatorname{Ret}}_{t}^{i}\right)^{2}
$$

where $v a r_{t}^{i}$ is the average variance (for each daily interval) during month $t$ for commodity $i$. This is estimated over $k$ daily intervals within month t. Similarly, we calculate the (average) realized covariances between commodity $i$ and the S\&P 500 during month $t$ as:

$$
\operatorname{covar}_{t}^{i, S \& P 500}=\frac{1}{k-1} \sum_{j=1}^{k}\left(\operatorname{Ret}_{j, t}^{i}-\overline{\operatorname{Ret}}_{t}^{i}\right)\left(\operatorname{Ret}_{j, t}^{S \& P 500}-\overline{\operatorname{Ret}}_{t}^{S \& P 500}\right)
$$

We subsequently calculate the hedge ratio for commodity $i$ and the S\&P 500 over the respective time period $\mathrm{t}$ as: 


$$
\begin{aligned}
\beta_{\mathrm{t}}^{\mathrm{i}, \mathrm{S} \& P 500} & =\frac{\operatorname{covar}_{t}^{i, S \& P 500}}{\operatorname{var}_{t}^{i}} \\
& =\frac{\sum_{j=1}^{k}\left(\operatorname{Ret}_{j, t}^{i}-\overline{\operatorname{Ret}}_{t}^{i}\right)^{2}}{\sum_{j=1}^{k}\left(\operatorname{Ret}_{j, t}^{i}-\overline{\operatorname{Ret}}_{t}^{i}\right)\left(\operatorname{Ret}_{j, t}^{S \& P 500}-\overline{\operatorname{Ret}}_{t}^{S \& P 500}\right)} .
\end{aligned}
$$

In our tests we always make sure that the hedge ratio is available in real time and hence the ratio calculated at time $t$ is applied to form a portfolio which is held during time $t+1$.

We need to ensure we can appropriately compare the hedge ratios from the three methodologies we implement and appropriately examine the time-series properties of these hedge ratios, which we do in Section 4. In order to achieve this we estimate the Multivariate GARCH and OLS models recursively using data for each time period (of 21 days). This enables us to avoid concerns relating to overlapping observations for the Realized Volatility and Multivariate GARCH models, which could induce non-stationary hedge ratios. Below we outline the methodology we undertook to calculate the hedge ratio from the multivariate GARCH model.

\subsection{Multivariate GARCH Model}

The second method we consider is the multivariate-GARCH (BEKK) model; We estimate the model such that the mean equation for the system is specified by the following:

$$
Y_{t}=C+A Y_{t-1}+V_{t}
$$

where $\mathbf{Y}_{\mathbf{t}}=\left(\mathrm{R}_{\mathrm{t}}^{\text {commodity }}, \mathrm{R}_{\mathrm{t}}^{\mathrm{S} \& \mathrm{P} 500}\right)^{\prime} \cdot \mathrm{R}_{, \mathrm{t}}^{\mathrm{i}}$ is the return of the commodity index and the S\&P 500 respectively. ${ }^{6} \mathbf{A}$ and $\mathbf{C}$ are $n \times n$ coefficient matrices and $\mathbf{V}_{\mathrm{t}}=\left(\varepsilon_{\mathrm{t}}^{\text {commodity }}, \varepsilon_{\mathrm{t}}^{\mathrm{S} \& P 500}\right)^{\prime}$ is a vector that contain the residuals from the mean equations in (5), such that each residual,

\footnotetext{
${ }^{6}$ The returns are cumulated over the 21 day intervals in time $t\left(R_{t}^{i}=\sum_{j=1}^{k} \operatorname{Ret}_{j, t}^{i}\right)$ and then the GARCH model is estimated. This is to allow comparability with the realized volatility hedge ratio estimates, which as shown in equation (4) can be stated in terms of cumulated returns.
} 


$$
\varepsilon_{\mathrm{t}}=\mathrm{h}_{\mathrm{t}}^{\frac{1}{2}} \eta_{\mathrm{t}}
$$

and each innovation $\eta_{i, t}$ is an i.i.d. random shock. Thus, (5) and (6) is simply a bivariate VAR-GARCH model of the S\&P 500 and the respective commodity index. We follow Engle and Kroner (1995) and use the BEKK ${ }^{7}$ specification to model the conditional variances:

$$
\mathbf{H}(\mathrm{t})=\mathbf{C}^{\prime} \mathbf{C}+\mathbf{A}^{\prime} \mathbf{u}(\mathrm{t}-1) \mathbf{u}^{\prime}(\mathrm{t}-1) \mathbf{A}+\mathbf{B}^{\prime} \mathbf{H}(\mathrm{t}-1) \mathbf{B}
$$

where $\mathbf{C}$ and $\mathbf{D}$ are lower triangular matrices and $\mathbf{A}$ and $\mathbf{B}$ are general $n \times n$ matrices. Thus, each term is positive semi-definite by construction. From (7) the conditional variance for the Energy and S\&P 500 returns is determined by past shocks and past conditional variances of the S\&P 500 return and Energy return and the dollar index. ${ }^{8}$ Thus, if one carries out the above matrix multiplications, the conditional variance of the energy index would be:

$$
h_{11 t}=\left(c_{11}^{2}+c_{12}^{2}\right)+b_{11}^{2} h_{11, t-1}+2 b_{11} b_{21} h_{12, t-1}+b_{21}^{2} h_{22, t-1^{1}}+\alpha_{11}^{2} \varepsilon_{1, t-1}^{2}+2 \alpha_{11} \alpha_{21} \varepsilon_{1, t-1} \varepsilon_{2, t-1}+\alpha_{21}^{2} \varepsilon_{2, t-1}^{2}
$$

To calculate the hedge ratio we follow Kroner and Sultan (1993), and Mensi et al. (2013) calculate hedge ratio for the S\&P 500 and each commodity index using the estimated conditional co variances. That is, in order to minimize the risk that is $\$ 1$ long the S\&P 500, the investor should short $\$ ß$ of the commodity indices. Thus, the hedge ratio is then:

$$
\beta_{\mathrm{t}}^{\text {commodity, } \mathrm{S} \& P 500}=\frac{\mathrm{h}_{\mathrm{t}}^{\text {commodity,S\&P500 }}}{\mathrm{h}_{\mathrm{t}}^{\text {commodity }}}
$$

However, in contrast to Mensi et al. (2013), we report the time-varying hedge ratios, which reflect changes in the conditional covariance and conditional variances of the series. If commodities are true hedges one would want the hedge ratios to stay relatively constant over the estimated time period.

\footnotetext{
${ }^{7}$ Other Multivariate models exist, such as CCC, DCC, or VAR-GARCH. We chose the BEKK model primarily because in order to implement the variance impulse response functions (VIRF) the multivariate GARCH model must be able to be transformed into a multivariate VECH model which the BEKK model accommodates.

${ }^{8}$ We also attempted to estimate a tri-variate GARCH model with a dollar return variance equation. We could not obtain convergence. This is not surprising as adding an extra variable results in the addition of a large number of parameters that must be estimated.
} 


\subsection{Recursive OLS}

In addition, we also calculated hedge ratios by recursively estimating OLS regressions. As such, we estimated the following:

$$
S \& P_{-} \operatorname{Ret}_{t}=\beta_{\mathrm{t}} \operatorname{Ret}_{i, t}+\varepsilon_{\mathrm{t}}
$$

where S\&P_Ret is the return of the S\&P 500 in period $t$, and $\operatorname{Ret}_{i, t}$ is the return of commodity $i$ in period t. Given the definition the hedge ratio above, $\beta_{t}$ is the estimated hedge ratio over period respective sample period. We estimated (9) recursively so as to allow the hedge ratio to be time varying. ${ }^{9}$

\subsection{Hedge Effectiveness, Risk and Performance Metrics}

To assess the performance of the hedges we consider the performance of a hedged portfolio $\left(P_{H}\right)$ compared to the benchmark of an unhedged portfolio $\left(P_{\mathrm{U}}\right) . P_{\mathrm{U}}$ simply has a portfolio weight of 1 in the S\&P 500; this portfolio earns a return of $\mathrm{R}_{\mathrm{U}} . P_{H}$ is a portfolio with a weight of 1 in the S\&P 500 and a weight of $-\mathrm{H}$ in commodity, where $\mathrm{H}$ is the hedge ratio; $P_{H}$, the hedge portfolio earns a return of $\mathrm{R}_{H}$. Please note that the hedge ratio is estimated in real-time, i.e. it is based only on information available prior to the portfolio being formed.

The variance measure (or hedge effectiveness) tells us what proportion of the variance of the portfolio is reduced by the hedge. It is calculated as:

$$
\frac{\sum_{t=1}^{T}\left(R_{U, t}-\bar{R}_{U}\right)-\sum_{t=1}^{T}\left(R_{H, t}-\bar{R}_{H}\right)}{\sum_{t=1}^{T}\left(R_{U, t}-\bar{R}_{U}\right)} .
$$

A positive value here indicates the hedge has reduced portfolio variance. For example a value of 0.05 would indicate the hedge has reduced portfolio variance by $5 \%$ compared to the unhedged portfolio.

\footnotetext{
${ }^{9}$ We did estimate rolling OLS hedges as well which performed in a qualitatively similar way to the recursive hedge.
} 
We also consider two measures of downside risk. First, the semi-variance measure which is defined as:

$$
\frac{\sum_{t=1}^{T}\left(R_{U, t}^{B M}-\bar{R}_{U}\right)-\sum_{t=1}^{T}\left(R_{H, t}^{B M}-\bar{R}_{H}\right)}{\sum_{t=1}^{T}\left(R_{U, t}^{B M}-\bar{R}_{U}\right)}
$$

Here $R^{B M}$ is equal to $\mathrm{R}$ when the return is less than or equal to the sample mean and is equal to the sample mean otherwise. A positive value of the semi-variance measure indicates the hedge has reduced portfolio variance on the downside. For example a value of 0.05 would indicate the hedge has reduced semi-variance by 5\% compared to the unhedged portfolio.

The second measure of downside risk is simply the sum of losses. Define $R^{-}$as equal to the $\mathrm{R}$ when the return is less than 0 and 0 otherwise. The sum of losses measure is then defined as:

$$
\frac{\sum_{t=1}^{T} R_{U, t}^{-}-\sum_{t=1}^{T} R_{H, t}^{-}}{\sum_{t=1}^{T} R_{U, t}^{-}}
$$

We finally consider two measures of portfolio performance. Firstly the increase in portfolio return defined as:

$$
\frac{\sum_{t=1}^{T} R_{H, t}-\sum_{t=1}^{T} R_{U, t}}{\sum_{t=1}^{T} R_{U, t}} .
$$

This measures the proportional increase in the portfolio return. For example a value of -0.1 indicates that hedging reduced portfolio return by $10 \%$ compared to the unhedged portfolio. Finally we consider the sum of gains. Define $R^{+}$as equal to the $\mathrm{R}$ when the return is greater than 0 and 0 otherwise. The sum of gains measure is then defined as:

$$
\frac{\sum_{t=1}^{T} R_{H, t}^{+}-\sum_{t=1}^{T} R_{U, t}^{+}}{\sum_{t=1}^{T} R_{U, t}^{+}}
$$

This sum of gains indicates if the hedge portfolio generates cumulatively more positive returns than the unhedged portfolio. 


\section{HEDGE RATIO TIME SERIES TESTS}

As noted above we constructed 21 day average returns so as to ensure that we would have equivalent time periods in which to compare the hedge ratios from the three methodologies discussed above. Figures 1-4 display the hedge ratios using the three above methodologies. Panel A in Table 1 displays the descriptive statistics of the constructed returns for the commodity futures returns used in our sample period; Panel B displays the sample statistics of the calculated hedge ratios from the three methodologies discussed above. The variable Average is the equally weighted average of the hedge ratios for each commodity for each of the three methodologies.

Note in Panel B of Table 1 the differences in the first and second moments of the hedge ratios. For instance, for every commodity the standard deviation of the hedge ratio using the recursive OLS methodology results in substantially lower standard deviations than the GARCH or realized volatility model. Not surprisingly, recursive OLS hedge ratios appear to be more stable given how much smaller the range of the minimum and the maximum each series.

\section{[INSERT TABLE 1 AND FIGURES 1-4]}

In order to better understand the properties of the hedge ratios, we also use unit root tests to determine whether the hedge ratios follow a random walk. Table 2 displays the results from estimating augmented Dickey-Fuller (ADF) tests along with the autocorrelation coefficient. The maximum number of lags considered was 24 and the lag length of the ADF test was determined using the Akaike Information Criteria (AIC). Somewhat surprisingly, the ADF tests are starkly different depending upon the model used to generate the hedge ratios for each of the commodities. For energy, the GARCH model and the realized volatility model both reject the random walk hypothesis whereas the OLS and the Average hedge ratios do 
not. Similarly, we reject the random walk hypothesis for the GARCH and realized volatility models for industrial metals but not for the recursive OLS or Average hedge ratios. For precious metals, only the realized volatility model rejects the random walk hypothesis. Whereas for agriculture and livestock, the GARCH, realized volatility, and average hedge ratios all reject the null hypothesis of a random walk but the OLS does not.

\section{[INSERT TABLE 2]}

As noted above, the third column in Table 2 displays the first order autocorrelation coefficient for each of the hedge ratios for each commodity. Note that a high autocorrelation coefficient would suggest that a hedge ratio in period $t$ will be highly correlated with the hedge ratio in period $t-1$. Thus, hedge ratios that are not very persistent would suggest that the portfolio manager must rebalance the portfolio regularly. However, hedge ratios that contain a unit root imply that the hedge ratio is random. Balancing a portfolio based on hedge ratios that do follow a random walk (i.e. contain a unit root) likely would have little, if any, positive impact on portfolio performance. Any improvement in portfolio performance would simply be luck. Note in Table 2 that stark differences in the first order autocorrelation coefficient from using each of the three methodologies. The autocorrelation coefficient for energy ranges from 0.16 to 0.98 , for industrial metals it ranges from 0.34 to 0.99 , for precious metals it ranges from 0.08 to 0.98 , for agriculture it ranges from 0.24 to 0.98 , and for livestock it ranges from 0.32 to 0.98 . Given the stark differences in the ADF tests and the differences in the autocorrelation coefficients, we chose to further test the effectiveness of each of the hedges by evaluating the performance of a synthetic portfolio of each of the commodities and the S\&P 500. 


\section{HEDGE PORTFOLIO EFFECTIVENESS AND PERFORMANCE}

We now examine directly the pivotal research question: are commodity futures an effective hedge for equity returns? We also further examine if the hedging of equities with commodities is costly in terms of reducing portfolio returns. In our tests we form a portfolio with a weight of $100 \%$ in the equity index and which is short $\mathrm{H} \%$ in the commodity, where $\mathrm{H}$ is the hedge ratio and compare these results to a benchmark which is simply long $100 \%$ in the equity index. It should be noted that this approach contrasts with the literature examining diversification with commodities since a long position (positive weight) in the commodity would be taken by such studies of diversification. We examine three measures of risk: variance, semi-variance and cumulative losses. Finally we examine two measure of return: mean and cumulative gains.

Table 3 provides an initial summary of our results for the full-sample period. The results for the variance from using Energy return as the hedge variable reveal that at best only a small portion of portfolio variance can be reduced. The best performing method for estimating the hedge here is the average of the GARCH, realized volatility and OLS hedge ratios; however even this can only reduce portfolio variance by $4.3 \%$. In contrast the results for realized volatility indicate a reduction of portfolio variance of $1 \%$ can be achieved, whereas the OLS and GARCH methods actually result in an increase of portfolio variance. The latter results are especially disconcerting since the whole point of hedging is to try and reduce portfolio fluctuations, not increase them. Nevertheless, the main message is that hedging with Energy commodities can, at best, only reduce a small fraction of the variance of the equity index.

We next consider the usefulness of industrial metals as a variance hedge for the equity 
index. Here, we find again that the average of all three hedge ratios provides the best results; overall it can reduce portfolio variance over the full sample period by just under $10 \%$. The OLS and GARCH methods can also reduce portfolio variance in this setting, while the realized volatility approach does not; this is the reverse to what we discovered when Energy was used as the hedge commodity. In summary while part of the equity portfolio variance can be hedged by industrial metals over the full sample, it is only a small amount. Consequently portfolio managers would be well advised to choose alternative hedging assets for the equity index given the limited portion of variance that is actually hedged!

For the remaining three commodity hedges we consider (Precious Metals, Agriculture and Livestock) the results are even weaker overall than for either Energy or Industrial Metals. The maximum amount of variance that can be hedged is $0.4 \%$ (Livestock-OLS), while the hedge actually increases portfolio volatility in 10 out of 12 cases and by increases it by more than 5\% in 3 cases (Precious Metals-GARCH, Precious Metals-Realized Volatilty and Agriculture- Realized Volatility). This suggests that these commodities are very poor hedges for equity index volatility and cannot be recommended for implementation in practice.

We next consider two measures of downside portfolio exposure (semi-variance and cumulative losses). The results for these are very much in line with those for the variance metric. None of the commodity hedging approaches considered are able to substantially reduce equity portfolio risk. Energy commodities can reduce downside risk by less than 10\% in general and in fact there are just two cases for Energy which reductions are more than 5\% are possible; namely Realized volatility-semi-variance and Realized volatility-average of all. In terms of the Agriculture and Livestock commodity hedges reduce downside exposure by less than 5\%, whilst for Precious Metals all the purported hedges actually increase portfolio exposure to downside risk. The least bad performer is industrial metals but then even these are unable to reduce downside exposure to the equity index by more than $15 \%$ by the semi- 
variance measure or $6 \%$ by the cumulative loss measure.

The final two columns of Table 3 consider the impact of the hedging on the return performance. If the hedges were highly effective there would be concern about how much sacrifice was being made in terms of portfolio performance; however, given the poor hedging performance of the commodities and methods considered then the impact on return may be rather modest. For energy commodities there is little evidence that hedging with these substantially reduce portfolio performance; the largest reduction in mean performance is $10 \%$ (0.256 percentage point return decrease). However, the GARCH method actually leads to an increase of 30.4\% (about 0.768 percentage point return increase) in the mean performance. This suggests that while hedging may not be effective in terms of reducing risk, it suggests that during our full sample period that hedging was a better means of raising portfolio returns than diversification! However, the magnitude of performance change is much smaller when the cumulative gains measure is employed.

For Industrial Metals, the hedging tends to reduce portfolio performance in general but by a rather modest amount; never by more than $10 \%$. This seems broadly consistent with the industrial metals being able to hedge a very modest proportion of portfolio variance and there being some cost involved with that. For the Precious Metals, Agriculture and Livestock commodities the results are decidedly variable; in some cases the hedge substantially increases portfolio return by more than 15\% (e.g. Agriculture-Realized Volatility-Mean and Livestock-Realized Volatility-Mean) whereas in the case of Precious Metals the Realized Volatility measure reduces portfolio return by 39.2\% (or about 1 percentage point)! Overall, while hedging tends not to impact return measures in any one direction there is substantial variation in the performance of different metrics.

\section{[INSERT TABLE 3]}


Table 4 provides sub-period analysis. Panel A covers from 1990-2002 while Panel B covers from 2002-2014. In general Panel A suggests that hedging performance during the first part of the sample was even worse than the full sample. For example none of the Energy hedge approaches is able to reduce portfolio volatility during the 1990-2002 period, all of them lead to an increase in volatility, downside risk and cumulative losses compared to an unhedged position. The least worst hedge approach using Energy commodities is the OLS procedure, however, even this increases portfolio risk by over $2 \%$ according to any of the 3 risk measures considered; in contrast substantial increases in risk are recorded if the GARCH or Realized Volatility hedges are implemented which range from more than $5 \%$ in terms of cumulative losses to over $20 \%$ for the semi-variance.

The performance of the other commodities for hedging is also very disappointing over the 1990-2002 sub-sample. There is very little evidence that hedging during this period was able to reduce portfolio risk by an economically meaningful amount and typically portfolio risk actually increased if a hedge was implemented (in about $80 \%$ of cases). The maximum risk reduction was a paltry 4.2\% (OLS-Industrial Metals-Semi-variance). In general, similarly to the Energy hedge, the OLS method provides the least worst hedge. In contrast, the GARCH and Realized Volatility procedures uniformly lead to an increase in risk if a hedge is implemented across all four hedge commodities and all three risk measures.

In terms of return performance, implementing the hedge has in general a modest impact; the two notable exceptions are Realized Volatility-Energy-Mean and Realized Volatility-Precious Metals-Mean where a substantial sacrifice of return performance is made for implementing the hedge. However, the two best return performance results also involve the Realized Volatility method with Agriculture and Livestock as the hedge commodity respectively; this leads to an increase in return performance of more than $5 \%$ compared to the unhedged portfolio. Overall for the 1990-2002 sub-sample period the cross-hedges we 
consider do not lead to a reduction in portfolio volatility nor do they lead to substantial increases in portfolio performance either.

Panel B reports results for the 2002-2014 sub-period. These results seem to be slightly more promising than the almost uniformly poor results reported for the 1990-2002 subperiod. In terms of portfolio risk, there is some evidence that Energy and Industrial Metals can reduce portfolio risk be $10 \%$ or more if the average hedge ratio is implemented; this applies to both the variance and the semi-variance measure. In contrast the amount of risk that can be reduced by using the other commodities as a hedging instrument is decidedly limited; for example the average hedge ratio for Livestock reduces risk by all three measures over the 2002-2014 sub-period but the magnitude of the risk reduction never exceeds 5\% (using the average method the max. is $4.6 \%$ for semi-variance).

For the 2002-2014 sub-period there is some evidence that portfolio performance can be substantially impacted if a hedge is implemented. For example for Energy-GARCH the mean return is increased by $94.2 \%$ (i.e. from $1.4 \%$ to $2.7 \%$ ) or by more than $40 \%$ (from $1.4 \%$ to $1.9 \%$ ) in several cases. In contrast the impact in terms of the cumulative gains is much more modest with none of the hedges impacting cumulative gains by more than $10 \%$. Overall, it seems as if implementing hedges with commodities would have been more effective during the 2002-2014 sub-period than the 1990-2002 sub-period, nonetheless the overall performance of the hedges are rather weak in terms of the amount of portfolios risk which can be reduced, although in a couple of instances they may have had the unintended consequence of substantially increasing portfolio return.

\section{[INSERT TABLE 4]}

The Figures show time variation in the performance of a hedged portfolio using different commodities while in each diagram the estimation method is held fixed. The Figures 
are constructed in such a way that the final point gives the full sample value for the hedge commodity-estimation method-risk/return measure considered.

Figure 6 displays the portfolio volatility measure over time. The graphs suggest that only hedging with industrial metals can reduce portfolio variance by anything more than $4 \%$ relative to the full sample variance of the unhedged portfolio. The risk reduction obtained by industrial metals however is concentrated after January 2007 and in particular there is a spike in 2007-2008 that can account for approaching half of the overall risk reduction. Between 2007 and 2012 there is some risk reduction achieved by using industrial metals although any ongoing benefits from the hedge seems to have largely stabilized at 0 for the 2012 - mid 2014 period. Hence even for industrial metals where there is a small benefit offered from hedging, this is heavily concentrated in the 2007-2012 period.

Figure 7 displays the portfolio semi-variance measure over time. The results appear generally very consistent with those from the portfolio volatility measure. Overall, the industrial metals hedge is the least worst. Any substantive benefit from the industrial metals hedge in terms of risk reduction is during the 2007-2011 period and the effect of the spike about 2007 is even more pronounced for the semi-variance measure. These trends for Industrial Metals are apparent across all of the hedge measures estimated. The only other point of note is that there is a little evidence that the Energy hedge estimated via the Realized Volatility also does well over the post-2007 period, however, it performed the worst up until 2007. Figure 8 reveals that in terms of the sum of losses measure that the performance is weaker than for the semi-variance measure of downside risk. For the sum of losses the hedges are almost uniformly poor and unable to substantially offset the S\&P500 returns when they are suffer (substantial) losses); these results suggest that it is very difficult for commodities to hedge large negative returns suffered by the equity market. 


\section{[INSERT FIGURES 6-9]}

Figure 9 provides evidence of the portfolio return implications of the hedges. These suggest that the hedges have very little impact upon returns until about 2007. Since 2007 there is little evidence that the Industrial Metals hedge was costly in terms of return, even though during the post-2007 period it offered a very modest ability to reduce portfolio risk. There is some evidence that the hedges using Energy and Livestock were able to increase portfolio performance post-2007 (except for the OLS REC measure). Hence, although the hedges using Energy or Livestock may not have been effective in terms of risk reduction, they seem to offer some return benefits post-2007. However, it is questionable whether these return performance benefits from hedging with Energy or Livestock will be repeated in the future. In general the results suggest that while hedging with commodities do not dramatically adversely affect portfolio return, in terms of hedging portfolio risk they generally do not perform at all well. Hence we would suggest that better hedge assets than commodities exist for the S\&P 500.

\section{CONCLUSION}

This paper uses dynamic hedge ratios to examine if the risk of the S\&P 500 can be effectively hedged using commodity futures. We examine time-varying hedge ratios and how much portfolio risk can be reduced relative to a long position in the S\&P 500. An increase in (absolute) correlations between commodities and the S\&P 500, as has been documented for recent years, should make commodities more effective hedges; long S\&P 500 and short commodity futures. However, our results suggest that the financialization of commodities has not sufficiently impacted the relationship between commodities and S\&P 500 to make commodity futures highly effective hedges for the equity index. This finding is of 
considerable interest both to academics and practitioners. Firstly, many recent studies report hedge ratios between the equity market and the commodity market (see for example Sadorsky, 2014; Mensi et al., 2013); however, implementing cross-hedges in real-time seems to be of limited practical benefit in the Equity Index-Commodity case supporting prior evidence of $\mathrm{Wu}$ et al. (2011) on hedging Corn with Crude Oil. Secondly, equity market investors and asset managers looking for a way to manage and reduce portfolio risk will be well advised to search for alternative hedges for the S\&P 500 than commodity futures. 


\section{BIBLIOGRAPHY}

Aggarwal, R., Inclan, C., Leal, R., 1999. Volatility in emerging stock markets. Journal of Financial and Quantitative Analysis, 34, 33-55.

Alexander, C., Prokopczuk, M., Sumawong, A., 2013. The (de)merits of minimum-variance hedging: application to crack spread. Energy Economics, 36, 698-707

Baillie, R. T. and Myers, R. J. 1991. Bivariate GARCH estimation of the optimal commodity futures hedge. Journal of Applied Econometrics. 6, 109-24.

Bollerslev, T., 1982. Generalized autoregressive conditional heteroskedacity. J. Econ. 31, 301-327.

Chang, C.-L., Khamkaew, T., Tansuchat, R., McAleer, M., 2011. Interdependence of international tourism demand and volatility in leading ASEAN destinations. Tourism Economics. 17 (3), 481507.

Creti, A., Joëts, M., and Mignon, V. 2013. On the links between stock and commodity markets’ volatility. Energy Economics 37, 16-28.

Ederington, L. H. 1979. The hedging performance of the new futures markets. Journal of Finance. 34, 157-70.

Engle, R.F., 1982. Autoregressive conditional heteroskedasticity with estimates of the variance of United Kingdom inflation. Econometrica. 50, 987-1007.

Engle, R. F. and Kroner, K. F. 1995. Multivariate simultaneous generalized ARCH. Econometric Theory. 11, 122-50.

Erb, C.B., Harvey, C.R., 2006. The strategic and tactical value of commodity futures. Financial Analysts Journal, March, 69-97.

Ewing, B.T., Malik, F., 2005. Re-examining the asymmetric predictability of conditional variances:

The role of sudden changes in variance. Journal of Banking and Finance, 29, 2655-2673.

Fama, E.F., 1965. The behaviour of stock market prices. Journal of Business. 38, 34-105.

Fuertes, A-M., Miffre, J, and Rallis, G., 2010. Tactical Allocation in Commodity Futures Markets: Combining Momentum and Term Structure Signals, Journal of Banking and Finance, 34, 25302548.

Gagnon, L., Lypny, G. J. and McCurdy, T. H. 1998. Hedging foreign currency portfolios, Journal of Empirical Finance. 5, 197-220.

Gilbert, C. L. 2010. How to understand high food prices. Journal of Agricultural Economics, 61, 398425.

Gorton, G.B., Rouwenhorst, K.G., 2006. Facts and Fantasies about Commodity Futures, Financial Analysts Journal, March, 47-68.

Ghosh, A. 1993. Hedging with stock index futures: estimation and forecasting with error correction model. Journal of Futures Markets. 13, 743-52.

Haigh, M.S., Holt, M.T., 2000. Hedging multiple price uncertainty in international grain trade. Am. J. Agric. Econ. 82 (4), 881-889.

Haigh, M.S., Holt, M.T., 2002. Crack spread hedging: accounting for time varying volatility spillovers in the energy futures markets. Journal of Applied Econometrics. 17, 269-289.

Herbst, A.F., Kare, D.D., Caples, S.C., 1989. Hedging effectiveness and minimum risk hedge ratios in 
the presence of autocorrelation: foreign currency futures. J. Finance Eng. 9 (3), 185-197.

Hill, J., Schneeweis, T., 1982. The hedging effectiveness of foreign currency futures. Journal of Financial Research, 5, 95-104.

Huang, B.N., Yang, C.W., 2001. The impact of settlement time on the volatility of stock market revisited. An application of the iterated cumulative sums of squares detection method for changes of variance. Applied Economic Letters. 8, 665-668.

Ji, Q., Fan, Y., 2011. A dynamic hedging approach for refineries in multiproduct oil markets. Energy 36, 881-887.

Jensen, G., Johnson, F., \& Mercer, J. 2000. Efficient use of commodity futures in diversified portfolios. Journal of Futures Markets. 20(5), 489-506.

Johnson, L.L., 1960. The theory of hedging and speculation in commodity futures. Review of Economic Studies. 27 (3), 139-151.

Jones, C., and Kaul, G. (1996). Oil and stock markets. Journal of Finance. 51, 463-491.

Kroner, K. F. and Sultan, J. 1993. Time-varying distributions and dynamic hedging with foreign currency futures. Journal of Financial and Quantitative Analysis. 28, 535-51.

Lamoureux, C., Lastrapes, W., 1990. Persistence in variance, structural change, and the GARCH model. J. Bus. Econ. Stat. 8, 225-234

Lee, H.-T., 2009. Optimal futures hedging under jump switching dynamics. Journal of Empirical Finance. 16, 446-456.

Lee, H.-T., 2010, Regime switching correlation hedging. Journal of Banking and Finance. 34, 27282741.

Lee, H.-T. \& J. K. Yoder, 2007a, A bivariate Markov regime switching GARCH approach to estimate time varying minimum variance hedge ratios. Applied Economics. 39, 1253-1265.

Lee, H.-T. \& J. K. Yoder, 2007b, Optimal hedging with a Markov regime switching time-varying correlation. Journal of Futures Markets. 27, 495-516.

Lien, D., 1996. The effect of cointegration relationship on futures hedging: a note. Journal of Futures Markets. 16, 773-780.

Lien, D., 2005a. A note on the superiority of the OLS hedge ratio. Journal of Futures Markets. 25, 1121-1126.

Lien, D., 2005b. The use and abuse of the hedging effectiveness measure. International Review of Financial Analysis. 14, 277-282.

Lien, D., 2006. Estimation bias of futures hedging performance: a note. Journal of Futures Markets. 26, 835-841.

Lien, D., 2009. A note on the hedging effectiveness of GARCH models. International Review of Economics and Finance. 18, 110-112.

Lien, D. and Shrestha, K. 2010. Estimating optimal hedge ratio: a multivariate skew-normal distribution approach. Applied Financial Economics. 20, 627-36.

Lien, D., Lee, G. Yang, L. and Zhou, C. Evaluating the Effectiveness of Futures Hedging, in Handbook of Econometrics and Statistics, (2014)

Mensi, W., Beljid, M., Boubaker, A. And Managi, S., 2013. Correlations and volatility spillovers across commodity and stock markets: Linking energies, food and gold. Economic Modelling 32, 
$15-22$

Myers, R. J. 1991. Estimating time-varying optimal hedge ratios on futures markets. The Journal of Futures Markets. 11, 39-53.

Olson, E., Vivian, A.J., Wohar, M.E., 2014. The Relationship Between Energy and Equity Markets: Evidence from Volatility Impulse Response Functions, Energy Economics, 43, 297-305

Park,T. H., and L.N. Switzer. 1995. Time-Varying Distributions and the Optimal Hedge Ratios for Stock Index Futures. Applied Financial Economics. 5, 131-137

Sadorsky, P., 2014. Modeling volatility and correlations between emerging market stock prices and the prices of copper, oil and wheat. Energy Economics, 43, 72-81.

Sanso A., Arago, V., Carrion, L., 2004. Testing for changes in the unconditional variance of financial time series. Revista de Economia Financiera, 4, 32-53.

Silvennoinen A. and Thorp, S., 2013. Financialization, Crisis and Commodity Correlation Dynamics, Journal of International Financial Markets Institutions and Money, 24, 42-65.

Stein, J.L., 1961. The simultaneous determination of spot and futures prices. American Economic Review. 51, 1012-1025.

Tang K. and Xiong, W., 2012. Index investment and the financialization of commodities. Financial Analyst Journal, 68, 54-74.

Vivian, A., Wohar, M.E., 2012. Commodity volatility breaks. Journal of International Financial Markets, Institutions, and Money, 22(2), 395-422.

Wilson, B., Aggarwal, R., Inclan, C., 1996. Detecting volatility changes across the oil sector. The Journal of Futures Markets. 16, 313-330.

Wu, F., Guan, Z., \& Myers, R. J., 2011. Volatility spillover effects and cross hedging in corn and crude oil futures. Journal of Futures Markets, 31(11), 1052-1075. 
TABLE 1. Descriptive Statistics

\begin{tabular}{|c|c|c|c|c|c|c|c|c|}
\hline \multicolumn{9}{|c|}{ Panel A: Sample statistics - Returns } \\
\hline Variable & Nobs & Mean & SD & Min & Q1 & Med & Q3 & Max \\
\hline S\&P 500 & 367 & 0.029 & 0.220 & -1.242 & -0.068 & 0.061 & 0.142 & 0.745 \\
\hline Energy & 367 & 0.016 & 0.410 & -1.625 & -0.226 & 0.037 & 0.251 & 2.279 \\
\hline Industrial Metals & 367 & 0.024 & 0.296 & -1.328 & -0.148 & 0.016 & 0.185 & 1.790 \\
\hline Precious Metals & 367 & 0.006 & 0.210 & -0.987 & -0.120 & -0.018 & 0.139 & 0.833 \\
\hline Agriculture & 367 & -0.015 & 0.239 & -0.926 & -0.159 & -0.019 & 0.109 & 1.237 \\
\hline Livestock & 367 & -0.003 & 0.185 & -0.702 & -0.110 & 0.007 & 0.118 & 0.775 \\
\hline \multicolumn{9}{|c|}{ Panel B: Sample statistics - Hedge Ratios } \\
\hline Variable & Nobs & Mean & SD & Min & Q1 & Med & Q3 & Max \\
\hline \multicolumn{9}{|l|}{ Energy } \\
\hline GARCH & 307 & -0.027 & 0.115 & -0.563 & -0.082 & -0.027 & 0.030 & 0.566 \\
\hline Real. Vol. & 307 & 0.070 & 0.216 & -0.799 & -0.063 & 0.028 & 0.175 & 0.744 \\
\hline OLS & 307 & -0.043 & 0.048 & -0.117 & -0.085 & -0.044 & -0.018 & 0.042 \\
\hline Average & 307 & 0.000 & 0.095 & -0.312 & -0.055 & -0.018 & 0.042 & 0.412 \\
\hline \multicolumn{9}{|l|}{ Industrial Metals } \\
\hline$\overline{\text { GARCH }}$ & 307 & 0.137 & 0.158 & -0.327 & 0.051 & 0.146 & 0.215 & 1.206 \\
\hline Real. Vol. & 307 & 0.139 & 0.300 & -0.801 & -0.045 & 0.128 & 0.270 & 1.561 \\
\hline OLS & 307 & 0.116 & 0.053 & 0.052 & 0.074 & 0.108 & 0.125 & 0.217 \\
\hline Average & 307 & 0.131 & 0.133 & -0.201 & 0.045 & 0.122 & 0.204 & 0.771 \\
\hline \multicolumn{9}{|l|}{$\underline{\text { Precious Metals }}$} \\
\hline GARCH & 307 & -0.225 & 0.255 & -1.092 & -0.381 & -0.226 & -0.075 & 1.343 \\
\hline Real. Vol. & 307 & -0.076 & 0.354 & -2.491 & -0.267 & -0.064 & 0.126 & 0.828 \\
\hline OLS & 307 & -0.205 & 0.081 & -0.333 & -0.281 & -0.228 & -0.147 & -0.062 \\
\hline Average & 307 & -0.169 & 0.167 & -1.278 & -0.275 & -0.147 & -0.066 & 0.245 \\
\hline \multicolumn{9}{|l|}{ Agriculture } \\
\hline GARCH & 307 & 0.035 & 0.210 & -1.655 & -0.051 & 0.042 & 0.153 & 0.577 \\
\hline Real. Vol. & 307 & 0.067 & 0.291 & -0.636 & -0.093 & 0.043 & 0.206 & 1.499 \\
\hline OLS & 307 & 0.033 & 0.047 & -0.071 & -0.011 & 0.050 & 0.071 & 0.107 \\
\hline Average & 307 & 0.045 & 0.130 & -0.620 & -0.031 & 0.035 & 0.116 & 0.524 \\
\hline \multicolumn{9}{|l|}{ Livestock } \\
\hline$\overline{\text { GARCH }}$ & 307 & 0.147 & 0.249 & -0.482 & -0.019 & 0.116 & 0.251 & 0.937 \\
\hline Real. Vol. & 307 & 0.104 & 0.335 & -1.801 & -0.077 & 0.064 & 0.243 & 1.799 \\
\hline OLS & 307 & 0.064 & 0.033 & 0.007 & 0.033 & 0.058 & 0.095 & 0.112 \\
\hline Average & 307 & 0.105 & 0.150 & -0.441 & 0.014 & 0.079 & 0.177 & 0.942 \\
\hline
\end{tabular}


TABLE 2. Time Series Properties of Hedge Ratios

\begin{tabular}{|c|c|c|}
\hline \multirow[b]{2}{*}{ Variable } & \multicolumn{2}{|c|}{ First Order Autocorrelation Coefficient } \\
\hline & ADF Test & $\rho$ \\
\hline \multicolumn{3}{|l|}{ Energy } \\
\hline GARCH & $-9.63 * * *$ & 0.16 \\
\hline Real. Vol. & $-4.596 * * *$ & 0.59 \\
\hline OLS & -0.69 & 0.98 \\
\hline Average & -2.16 & 0.62 \\
\hline \multicolumn{3}{|c|}{ Industrial Metals } \\
\hline$\overline{\mathrm{GARCH}}$ & $-4.67 * * *$ & 0.34 \\
\hline Real. Vol. & $-3.57 * * *$ & 0.28 \\
\hline OLS & 0.23 & 0.99 \\
\hline Average & -1.80 & 0.47 \\
\hline \multicolumn{3}{|c|}{ Precious Metals } \\
\hline GARCH & -1.23 & 0.08 \\
\hline Real. Vol. & $-4.21 * * *$ & 0.23 \\
\hline OLS & -0.26 & 0.98 \\
\hline Average & -2.39 & 0.34 \\
\hline \multicolumn{3}{|c|}{ Agriculture } \\
\hline$\overline{\mathrm{GARCH}}$ & $-3.60 * * *$ & 0.56 \\
\hline Real. Vol. & $-8.69 * * *$ & 0.24 \\
\hline OLS & -1.86 & 0.98 \\
\hline Average & $-3.57 * * *$ & 0.49 \\
\hline \multicolumn{3}{|l|}{ Livestock } \\
\hline GARCH & $-6.38 * * *$ & 0.76 \\
\hline Real. Vol. & $-8.08 * * *$ & 0.32 \\
\hline OLS & -1.78 & 0.98 \\
\hline Average & $-6.32 * * *$ & 0.52 \\
\hline
\end{tabular}

Notes: This table provides results from estimating Augmented Dickey Fuller unit root tests and first order correlation coefficients. Statistical significance of the ADF tests suggests the series is stationary and is provided with $*(* *)[* * *]$ which indicates statistical significance at the $10 \%(5 \%)[1 \%]$ level. 
TABLE 3. Hedge Ratio Results - Full Sample

\begin{tabular}{|c|c|c|c|c|c|c|}
\hline & & \multicolumn{3}{|c|}{ Risk Measures } & \multicolumn{2}{|c|}{$\begin{array}{c}\text { Return } \\
\text { Measures }\end{array}$} \\
\hline Variable & Nobs & Variance & $\begin{array}{c}\text { Semi- } \\
\text { Variance }\end{array}$ & $\begin{array}{l}\text { Sum of } \\
\text { Losses }\end{array}$ & Mean & $\begin{array}{l}\text { Sum } \\
\text { of } \\
\text { Gains }\end{array}$ \\
\hline $\begin{array}{l}\text { Unhedged } \\
\text { Benchmark }\end{array}$ & 307 & 0.0473 & 0.0283 & -20.383 & 0.0256 & 28.217 \\
\hline $\begin{array}{l}\text { Improvement } \\
\text { Relative To } \\
\text { Benchmark (\%) }\end{array}$ & & Variance & $\begin{array}{c}\text { Semi- } \\
\text { Variance }\end{array}$ & $\begin{array}{l}\text { Sum of } \\
\text { Losses }\end{array}$ & Mean & $\begin{array}{l}\text { Sum } \\
\text { of } \\
\text { Gains }\end{array}$ \\
\hline Energy & & & & & & \\
\hline $\begin{array}{l}\text { GARCH } \\
\text { Real. Vol. } \\
\text { OLS } \\
\text { Average }\end{array}$ & & $\begin{array}{c}-0.052 \\
0.010 \\
-0.010 \\
0.043\end{array}$ & $\begin{array}{c}0.005 \\
0.073 \\
-0.011 \\
0.067\end{array}$ & $\begin{array}{c}0.010 \\
0.023 \\
-0.005 \\
0.031\end{array}$ & $\begin{array}{c}0.304 \\
-0.100 \\
-0.025 \\
0.056\end{array}$ & $\begin{array}{c}0.077 \\
-0.044 \\
-0.003 \\
-0.007\end{array}$ \\
\hline $\begin{array}{l}\text { Industrial Metals } \\
\text { GARCH } \\
\text { Real. Vol. } \\
\text { OLS } \\
\text { Average }\end{array}$ & & $\begin{array}{c}0.067 \\
-0.008 \\
0.089 \\
0.096\end{array}$ & $\begin{array}{l}0.092 \\
0.102 \\
0.112 \\
0.141\end{array}$ & $\begin{array}{l}0.024 \\
0.010 \\
0.046 \\
0.051\end{array}$ & $\begin{array}{r}-0.097 \\
0.089 \\
-0.065 \\
-0.026\end{array}$ & $\begin{array}{c}-0.044 \\
0.018 \\
-0.052 \\
-0.044\end{array}$ \\
\hline $\begin{array}{l}\text { Precious Metals } \\
\text { GARCH } \\
\text { Real. Vol. } \\
\text { OLS } \\
\text { Average }\end{array}$ & & $\begin{array}{l}-0.072 \\
-0.063 \\
-0.012 \\
-0.008\end{array}$ & $\begin{array}{l}-0.047 \\
-0.060 \\
-0.028 \\
-0.019\end{array}$ & $\begin{array}{l}-0.031 \\
-0.092 \\
-0.012 \\
-0.023\end{array}$ & $\begin{array}{c}0.165 \\
-0.392 \\
0.001 \\
-0.073\end{array}$ & $\begin{array}{c}0.068 \\
-0.043 \\
0.009 \\
-0.004\end{array}$ \\
\hline $\begin{array}{l}\text { Agriculture } \\
\text { GARCH } \\
\text { Real. Vol. } \\
\text { OLS } \\
\text { Average }\end{array}$ & & $\begin{array}{l}-0.023 \\
-0.073 \\
-0.003 \\
-0.001\end{array}$ & $\begin{array}{l}-0.016 \\
-0.035 \\
-0.001 \\
0.012\end{array}$ & $\begin{array}{l}-0.008 \\
-0.035 \\
-0.001 \\
-0.004\end{array}$ & $\begin{array}{r}-0.095 \\
0.174 \\
-0.011 \\
0.020\end{array}$ & $\begin{array}{c}-0.021 \\
0.074 \\
-0.002 \\
0.008\end{array}$ \\
\hline $\begin{array}{l}\text { Livestock } \\
\text { GARCH } \\
\text { Real. Vol. } \\
\text { OLS } \\
\text { Average }\end{array}$ & & $\begin{array}{l}-0.020 \\
-0.040 \\
0.004 \\
0.003\end{array}$ & $\begin{array}{l}0.000 \\
0.034 \\
0.012 \\
0.031\end{array}$ & $\begin{array}{c}-0.011 \\
-0.016 \\
0.005 \\
0.008\end{array}$ & $\begin{array}{l}0.076 \\
0.178 \\
0.030 \\
0.094\end{array}$ & $\begin{array}{l}0.029 \\
0.061 \\
0.004 \\
0.020\end{array}$ \\
\hline
\end{tabular}

Notes:

This table reports the relative improvement of using a hedged portfolio compare to the benchmark of an unhedged portfolio. The unhedged portfolio has a weight of 1 in the S\&P500. The hedged portfolio has a weight of 1 in the S\&P 500 and a weight of $-\mathrm{H}$ in the commodity, where $\mathrm{H}$ is the hedge ratio. Sum of Losses measure simply cumulates all the negative returns earnt by each portfolio and reports the improvement from the hedged position, while a similar approach is taken for the Sum of Gains which cumulates all positive returns earnt by each portfolio. Each measure is defined precisely in Section 3. 
TABLE 4. Hedge Ratio Results - Sub-sample

Panel A: Early sub-sample (c. 1990-2002)

\begin{tabular}{|c|c|c|c|c|c|c|}
\hline \multirow[b]{2}{*}{ Variable } & \multirow[b]{2}{*}{ Nobs } & \multicolumn{3}{|c|}{ Risk Measures } & \multicolumn{2}{|c|}{$\begin{array}{c}\text { Return } \\
\text { Measures }\end{array}$} \\
\hline & & Variance & $\begin{array}{c}\text { Semi- } \\
\text { Variance }\end{array}$ & $\begin{array}{l}\text { Sum of } \\
\text { Losses }\end{array}$ & Mean & $\begin{array}{c}\text { Sum of } \\
\text { Gains }\end{array}$ \\
\hline $\begin{array}{l}\text { Unhedged } \\
\text { Benchmark }\end{array}$ & 154 & 0.0418 & 0.0191 & -9.076 & 0.0365 & 14.701 \\
\hline $\begin{array}{l}\text { Improvement } \\
\text { Relative To } \\
\text { Benchmark (\%) }\end{array}$ & & Variance & $\begin{array}{c}\text { Semi- } \\
\text { Variance }\end{array}$ & $\begin{array}{l}\text { Sum of } \\
\text { Losses }\end{array}$ & Mean & $\begin{array}{c}\text { Sum of } \\
\text { Gains }\end{array}$ \\
\hline $\begin{array}{l}\text { Energy } \\
\text { GARCH } \\
\text { Real. Vol. } \\
\text { OLS } \\
\text { Average }\end{array}$ & & $\begin{array}{l}-0.097 \\
-0.093 \\
-0.024 \\
-0.034\end{array}$ & $\begin{array}{l}-0.201 \\
-0.218 \\
-0.029 \\
-0.101\end{array}$ & $\begin{array}{l}-0.063 \\
-0.093 \\
-0.035 \\
-0.043\end{array}$ & $\begin{array}{r}0.053 \\
-0.249 \\
-0.047 \\
-0.082\end{array}$ & $\begin{array}{c}0.059 \\
-0.038 \\
0.004 \\
-0.005\end{array}$ \\
\hline $\begin{array}{l}\text { Industrial Metals } \\
\text { GARCH } \\
\text { Real. Vol. } \\
\text { OLS } \\
\text { Average }\end{array}$ & & $\begin{array}{c}-0.014 \\
-0.058 \\
0.018 \\
0.008\end{array}$ & $\begin{array}{l}-0.020 \\
-0.081 \\
0.042 \\
0.007\end{array}$ & $\begin{array}{c}-0.020 \\
-0.063 \\
0.025 \\
-0.001\end{array}$ & $\begin{array}{r}-0.040 \\
0.037 \\
0.023 \\
0.006\end{array}$ & $\begin{array}{c}-0.003 \\
0.053 \\
-0.007 \\
0.003\end{array}$ \\
\hline $\begin{array}{l}\text { Precious Metals } \\
\text { GARCH } \\
\text { Real. Vol. } \\
\text { OLS } \\
\text { Average }\end{array}$ & & $\begin{array}{l}-0.095 \\
-0.001 \\
0.039 \\
0.025\end{array}$ & $\begin{array}{l}-0.091 \\
-0.022 \\
-0.014 \\
-0.014\end{array}$ & $\begin{array}{l}-0.070 \\
-0.052 \\
-0.039 \\
-0.036\end{array}$ & $\begin{array}{r}0.039 \\
-0.186 \\
-0.152 \\
-0.099\end{array}$ & $\begin{array}{r}0.058 \\
-0.039 \\
-0.034 \\
-0.016\end{array}$ \\
\hline $\begin{array}{l}\text { Agriculture } \\
\text { GARCH } \\
\text { Real. Vol. } \\
\text { OLS } \\
\text { Average }\end{array}$ & & $\begin{array}{l}-0.033 \\
-0.086 \\
-0.001 \\
-0.016\end{array}$ & $\begin{array}{c}-0.037 \\
-0.126 \\
0.005 \\
-0.025\end{array}$ & $\begin{array}{l}-0.033 \\
-0.052 \\
-0.007 \\
-0.018\end{array}$ & $\begin{array}{c}-0.073 \\
0.080 \\
0.006 \\
0.004\end{array}$ & $\begin{array}{c}-0.008 \\
0.063 \\
0.006 \\
0.013\end{array}$ \\
\hline $\begin{array}{l}\text { Livestock } \\
\text { GARCH } \\
\text { Real. Vol. } \\
\text { OLS } \\
\text { Average }\end{array}$ & & $\begin{array}{l}-0.018 \\
-0.084 \\
-0.004 \\
-0.011\end{array}$ & $\begin{array}{l}-0.025 \\
-0.051 \\
0.004 \\
0.004\end{array}$ & $\begin{array}{c}-0.042 \\
-0.051 \\
0.002 \\
-0.010\end{array}$ & $\begin{array}{c}-0.057 \\
0.077 \\
0.018 \\
0.013\end{array}$ & $\begin{array}{l}0.004 \\
0.061 \\
0.006 \\
0.011\end{array}$ \\
\hline
\end{tabular}

Notes:

This table reports the relative improvement of using a hedged portfolio compare to the benchmark of an unhedged portfolio. The unhedged portfolio has a weight of 1 in the S\&P500. The hedged portfolio has a weight of 1 in the S\&P 500 and a weight of $-\mathrm{H}$ in the commodity, where $\mathrm{H}$ is the hedge ratio. Sum of Losses measure simply cumulates all the negative returns earnt by each portfolio and reports the improvement from the hedged position, while a similar approach is taken for the Sum of Gains which cumulates all positive returns earnt by each portfolio. Each measure is defined precisely in Section 3. 
TABLE 4. Hedge Ratio Results - Sub-sample (continued)

Panel B: Later sub-sample (c. 2002-2014)

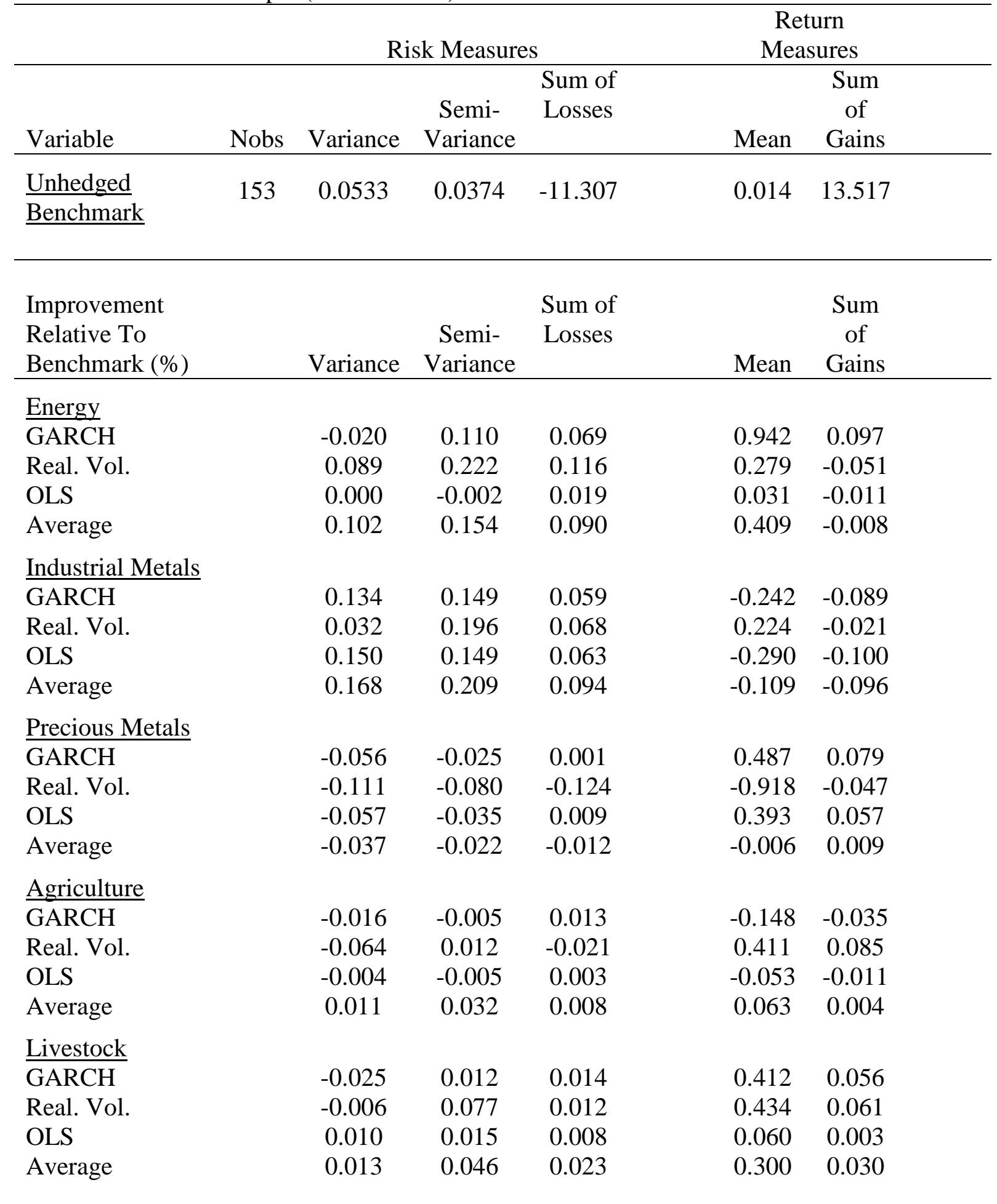

\section{Notes:}

This table reports the relative improvement of using a hedged portfolio compare to the benchmark of an unhedged portfolio. The unhedged portfolio has a weight of 1 in the S\&P500. The hedged portfolio has a weight of 1 in the S\&P 500 and a weight of $-\mathrm{H}$ in the commodity, where $\mathrm{H}$ is the hedge ratio. Sum of Losses measure simply cumulates all the negative returns earnt by each portfolio and reports the improvement from the hedged position, while a similar approach is taken for the Sum of Gains which cumulates all positive returns earnt by each portfolio. Each measure is defined precisely in Section 3. 


\section{Energy}

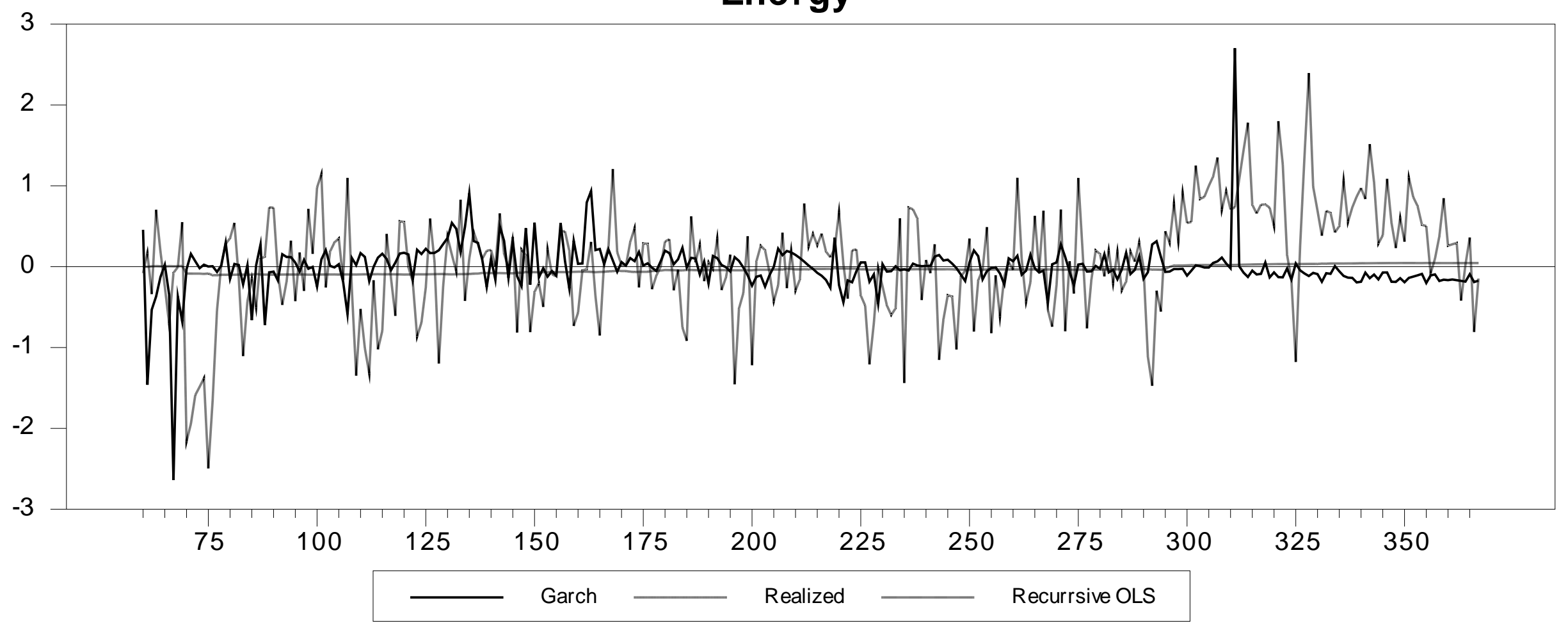

_Notes: This figure displays dynamic hedge ratios between the S\&P 500 and the Goldman Sach’s Energy Index using three different methodologies. The solid line are hedge ratios obtain from a multivariate-GARCH model; the dotted line are hedge ratios from realized (co)variances; and the dashed line are hedge ratios obtained from recursive OLS regressions(the beta coefficient). 


\section{Industrial Metals}

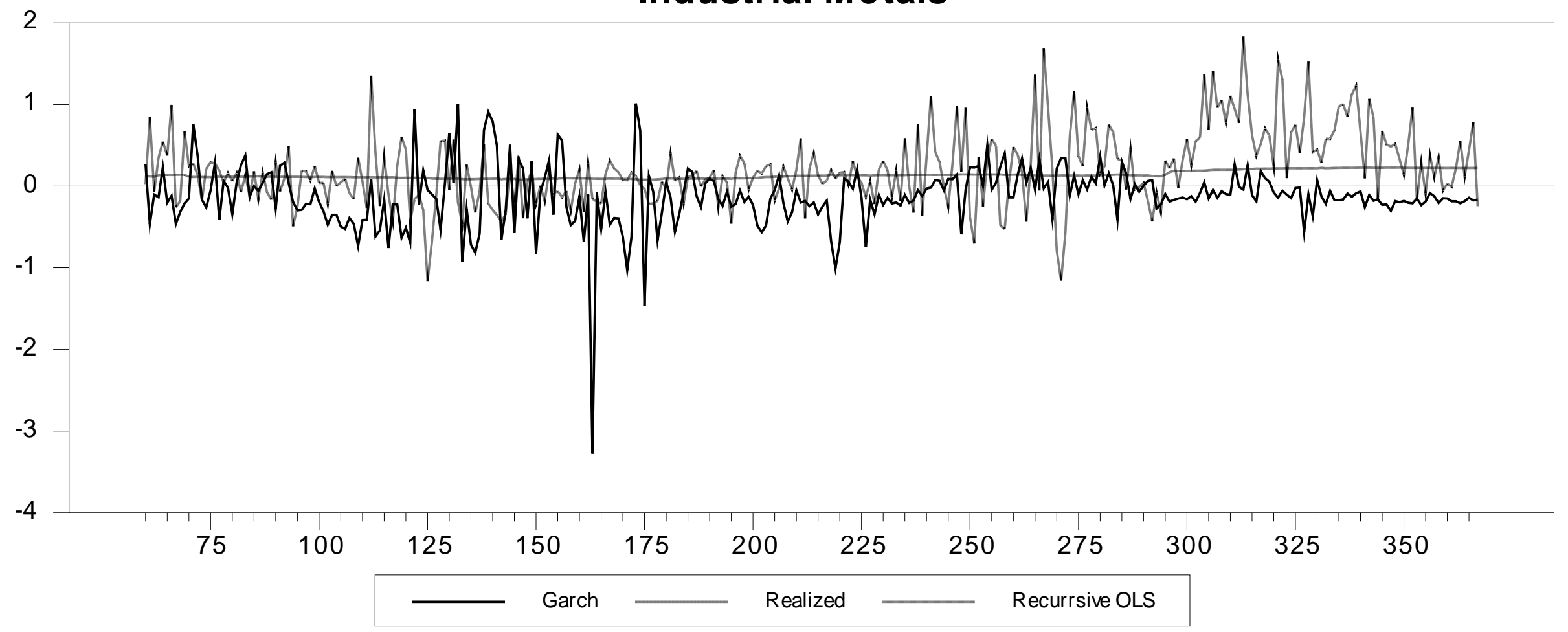

_Notes: This figure displays dynamic hedge ratios between the S\&P 500 and the Goldman Sach’s Industrial Metals Index using three different methodologies. The solid line are hedge ratios obtain from a multivariate-GARCH model; the dotted line are hedge ratios from realized (co)variances; and the dashed line are hedge ratios obtained from recursive OLS regressions(the beta coefficient). 


\section{Precious Metals}

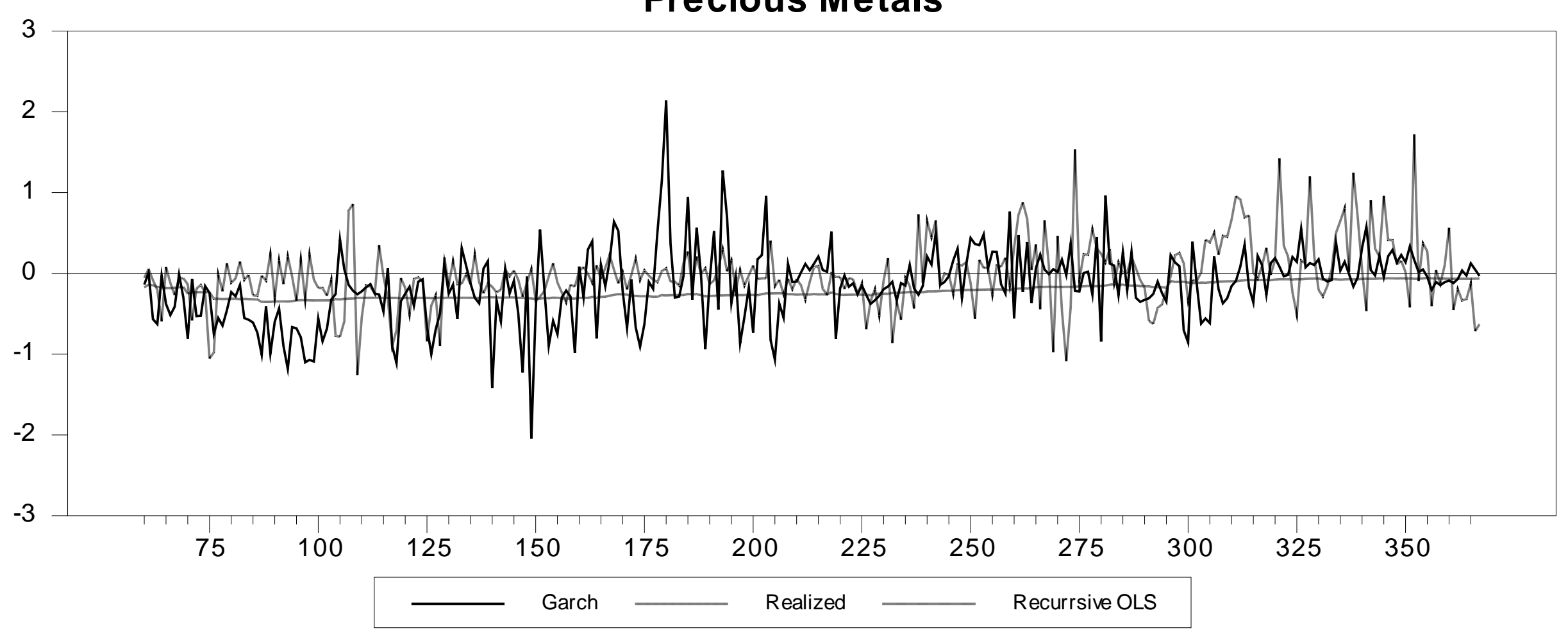

__Notes: This figure displays dynamic hedge ratios between the S\&P 500 and the Goldman Sach’s Precious Metals Index using three different methodologies. The solid line are hedge ratios obtain from a multivariate-GARCH model; the dotted line are hedge ratios from realized (co)variances; and the dashed line are hedge ratios obtained from recursive OLS regressions(the beta coefficient). 


\section{Agriculture}

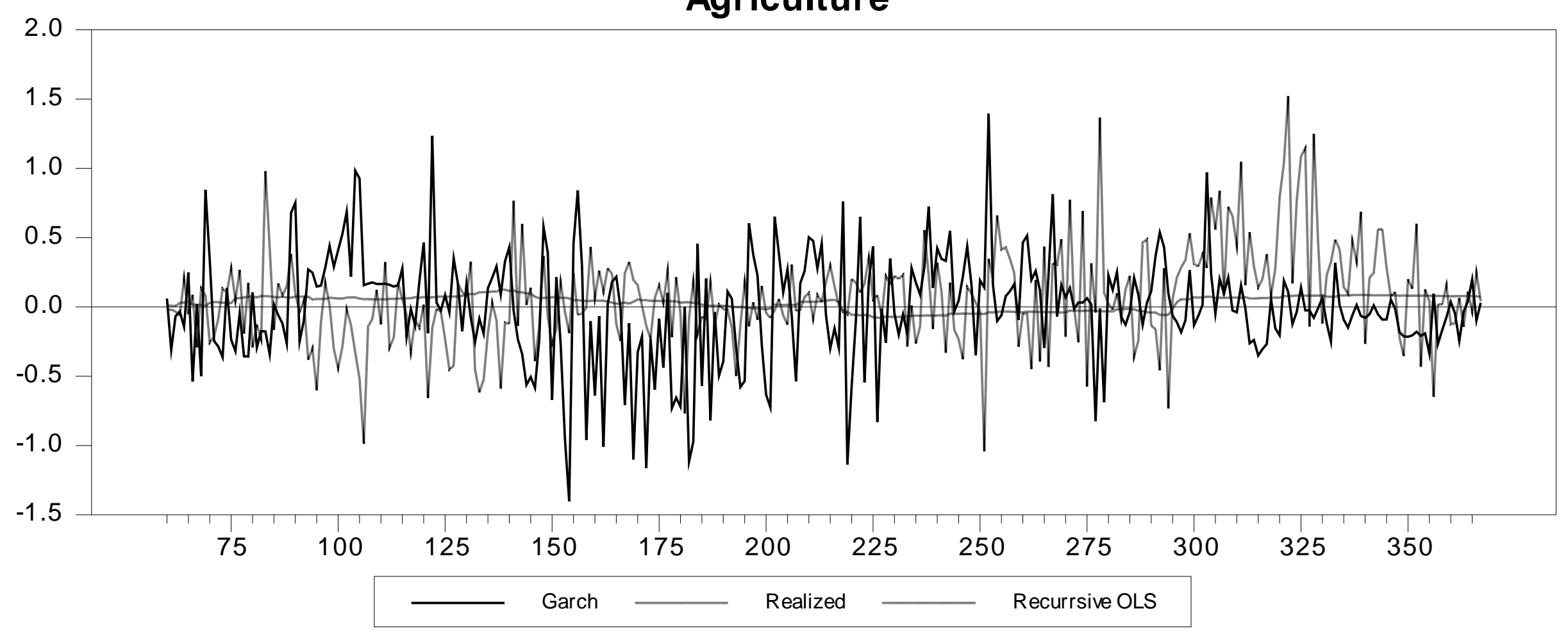

Notes: This figure displays dynamic hedge ratios between the S\&P 500 and the Goldman Sach’s Agricultural Index using three different methodologies. The solid line are hedge ratios obtain from a multivariate-GARCH model; the dotted line are hedge ratios from realized (co)variances; and the dashed line are hedge ratios obtained from recursive OLS regressions(the beta coefficient). 
Figure 5: Livestock and S\&P 500 Hedge Ratios

\section{Livestock}

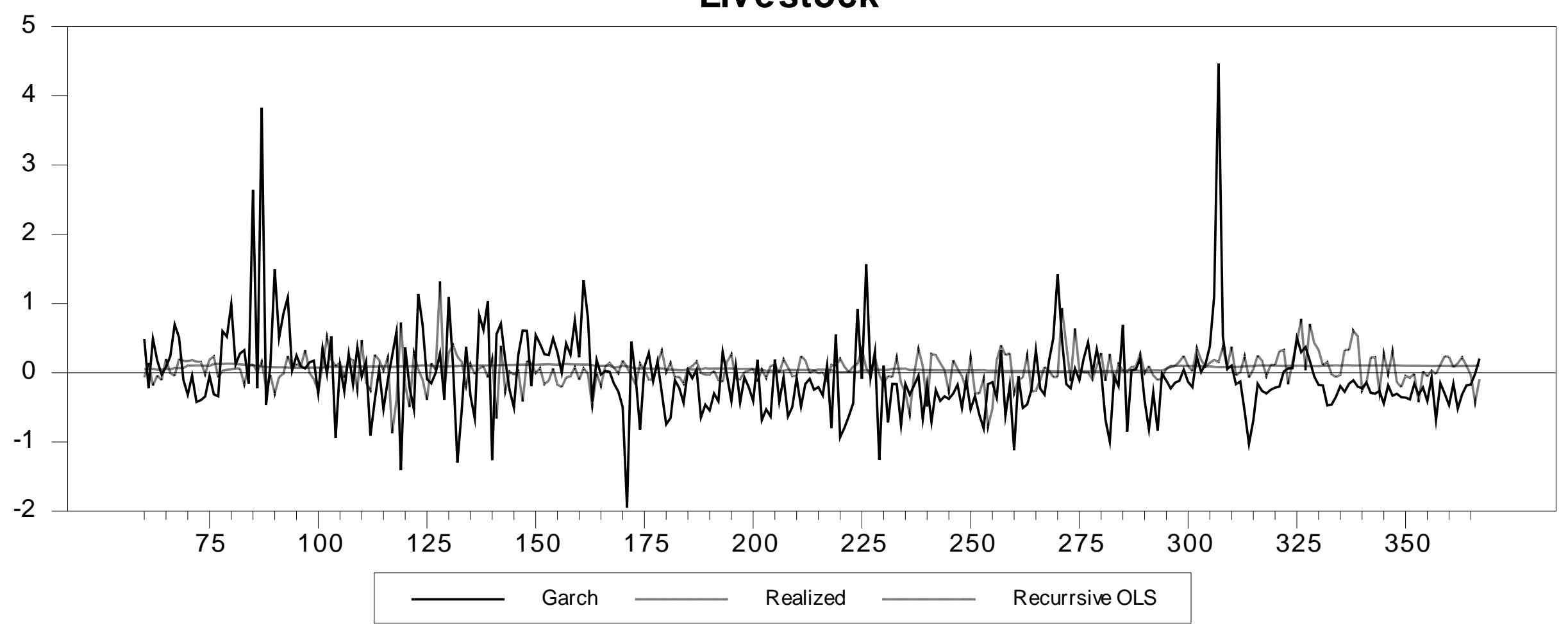

Notes: This figure displays dynamic hedge ratios between the S\&P 500 and the Goldman Sach’s Livestock Index using three different methodologies. The solid line are hedge ratios obtain from a multivariate-GARCH model; the dotted line are hedge ratios from realized (co)variances; and the dashed line are hedge ratios obtained from recursive OLS regressions(the beta coefficient). 


\section{FIGURE 6: HEDGING EFFECTIVENESS: MEASURES OF REDUCTIONS IN PORTFOLIO VOLATILITY.}
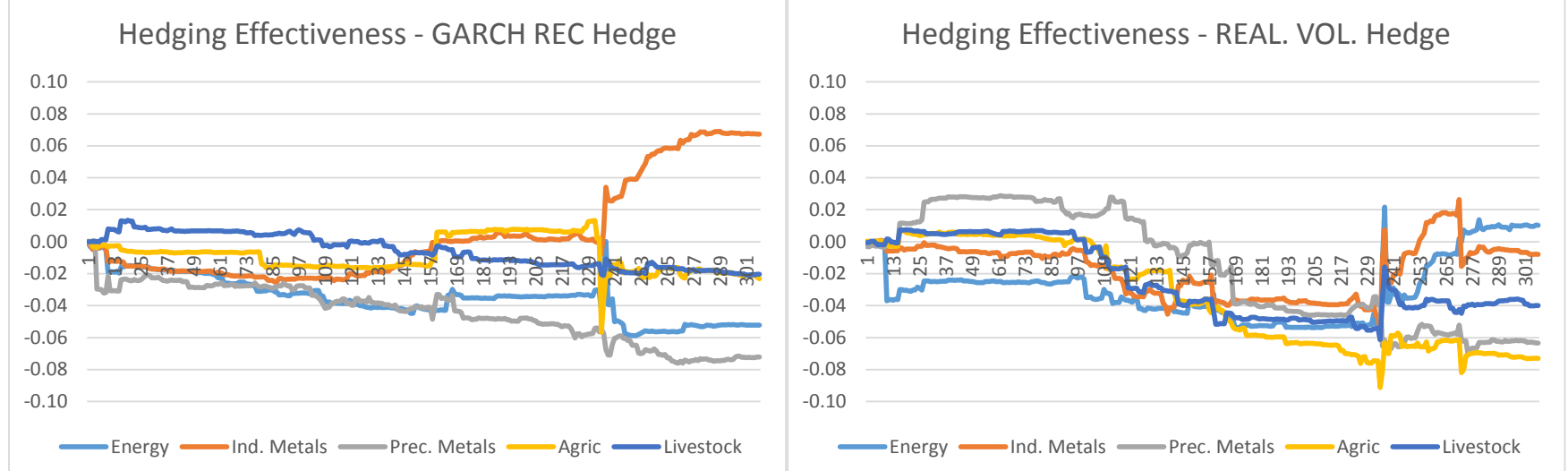

Hedging Effectiveness - OLS REC Hedge
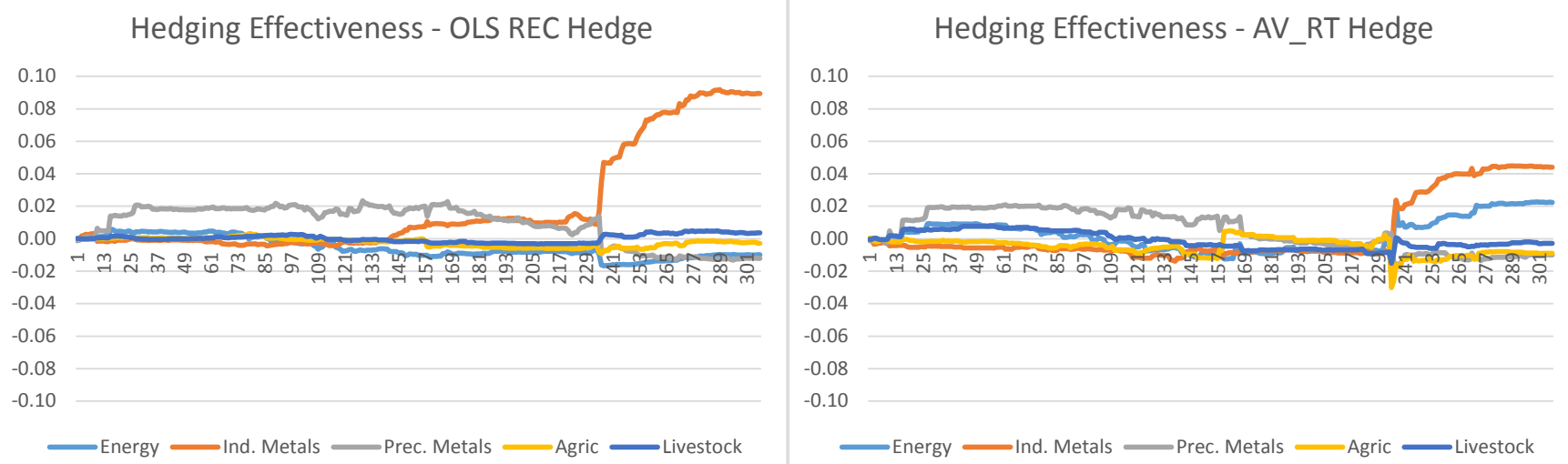

Notes: This figure depicts time-variation in the out-of-sample hedging effectiveness of commodities for the equity index using four different methods to estimate the hedge ratio. These are: i) recursive GARCH method (GARCH REC), ii) realized volatility from the last 21 trading days (REAL. VOL.), iii) recursive OLS (OLS REC) and iv) a simple average of methods i) through iii) denoted (AV_RT). For GARCH REC and OLS REC a start-up period of 60 observations is used (which then expands as time progresses).

The hedging effectiveness metric calculated in all graphs is: $\frac{\sum_{1}^{t}\left(R_{U, t}-\bar{R}_{U}\right)-\sum_{1}^{t}\left(R_{H, t}-\bar{R}_{H}\right)}{\sum_{1}^{T}\left(R_{U, t}-\bar{R}_{U}\right)}$

$$
\sum_{1}^{T}\left(R_{U, t}-\bar{R}_{U}\right)
$$

$R_{U}$ is the return to the unhedged portfolio, which has a weight of 1 in the S\&P 500. $R_{H}$ is the return to the hedged portfolio; this has a weight of 1 in the S\&P 500 and weight of $-\mathrm{H}$ in commodity, where $\mathrm{H}$ is the hedge ratio. This is basically the cumulative reduction in squared return deviations so far to period $t$, divided by the full sample squared return deviation. A positive value here indicates the hedge has reduced portfolio variance. An increase in this measure at period t indicates that the hedge reduced variance in period t. So in the final graph this tells us that using the AV_RT method, the hedge using industrial metals reduces portfolio volatility by over $4 \%$ over the full-sample. 


\section{FIGURE 7: HEDGING DOWNSIDE RISK (MEASURES OF REDUCTIONS IN SEMI-VARIANCE).}

Hedging Downside

Effectiveness - GARCH REC Hedge

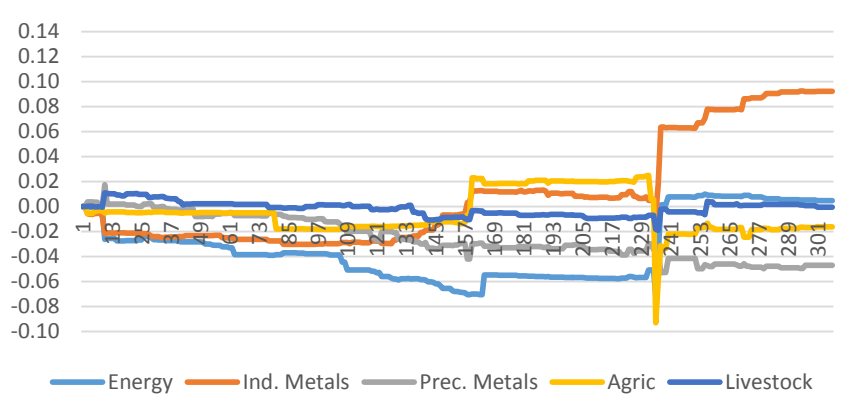

Hedging Downside

Effectiveness - OLS REC Hedge

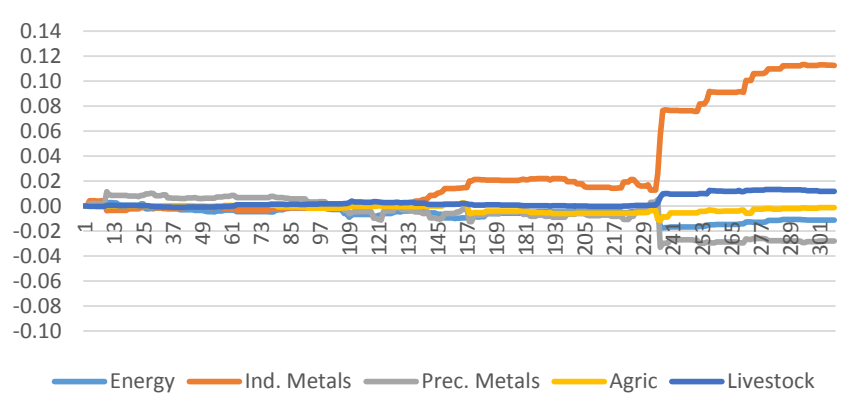

Hedging Downside

Effectiveness - REAL. VOL. Hedge

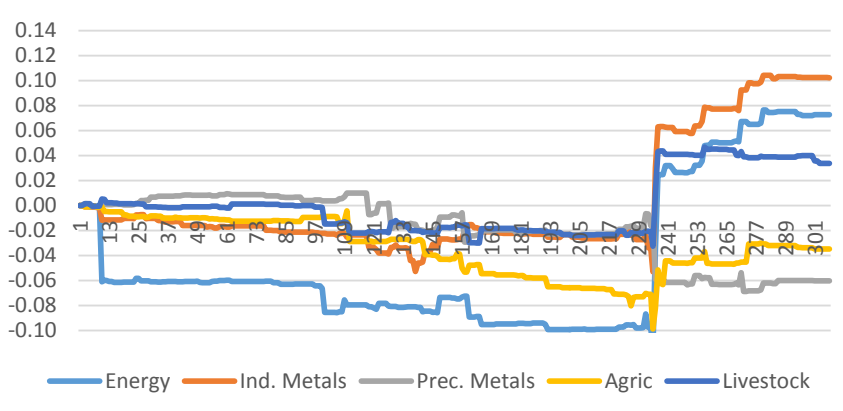

Hedging Downside

Effectiveness - AV_RT Hedge

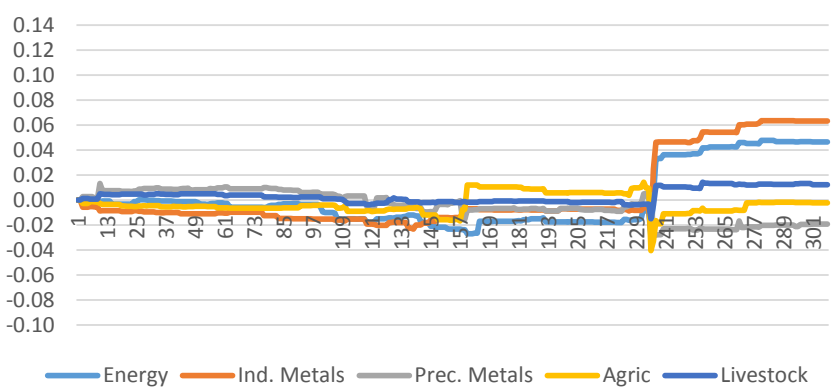

Notes: This figure depicts time-variation in the out-of-sample ability of a commodities hedge for the equity index to reduce semi-variance using four different methods to estimate the hedge ratio. These are: i) recursive GARCH method (GARCH REC), ii) realized volatility from the last 21 trading days (REAL. VOL.), iii) recursive OLS (OLS REC) and iv) a simple average of methods i) through iii) denoted (AV_RT). For GARCH REC and OLS REC a start-up period of 60 observations is used (which then expands as time progresses).

The semi-variance metric calculated in all graphs is: $\frac{\sum_{1}^{t}\left(R_{U, t}^{B M}-\bar{R}_{U}\right)-\sum_{1}^{t}\left(R_{H, t}^{B M}-\bar{R}_{H}\right)}{\sum^{T}\left(R_{U, t}^{B M}-\bar{R}_{U}\right)}$

$$
\sum_{1}^{T}\left(R_{U, t}^{B M}-\bar{R}_{U}\right)
$$

$R^{B M}$ is equal to $\mathrm{R}$ when the return is less than or equal to the sample mean and is equal to the sample mean otherwise. $R_{U}$ is the return to the unhedged portfolio, which has a weight of 1 in the $\mathrm{S} \& \mathrm{P} 500 . R_{H}$ is the return to the hedged portfolio; this has a weight of 1 in the S\&P 500 and weight of $-\mathrm{H}$ in commodity, where $\mathrm{H}$ is the hedge ratio. The semi-variance metric is the cumulative reduction in semi-variance to period t, divided by the full sample semi-variance. A positive value here indicates the hedge has reduced portfolio semi-variance. An increase in this measure at period $t$ indicates that the hedge reduced semi-variance in period t. So in the final graph this tells us that using the AV RT method, the hedge using industrial metals reduces portfolio volatility by over $6 \%$ over the full-sample. 


\section{FIGURE 8: HEDGING OF LOSSES EFFECTIVE (SUM OF RET. LOSSES REL. TO NON-HEDGE)}

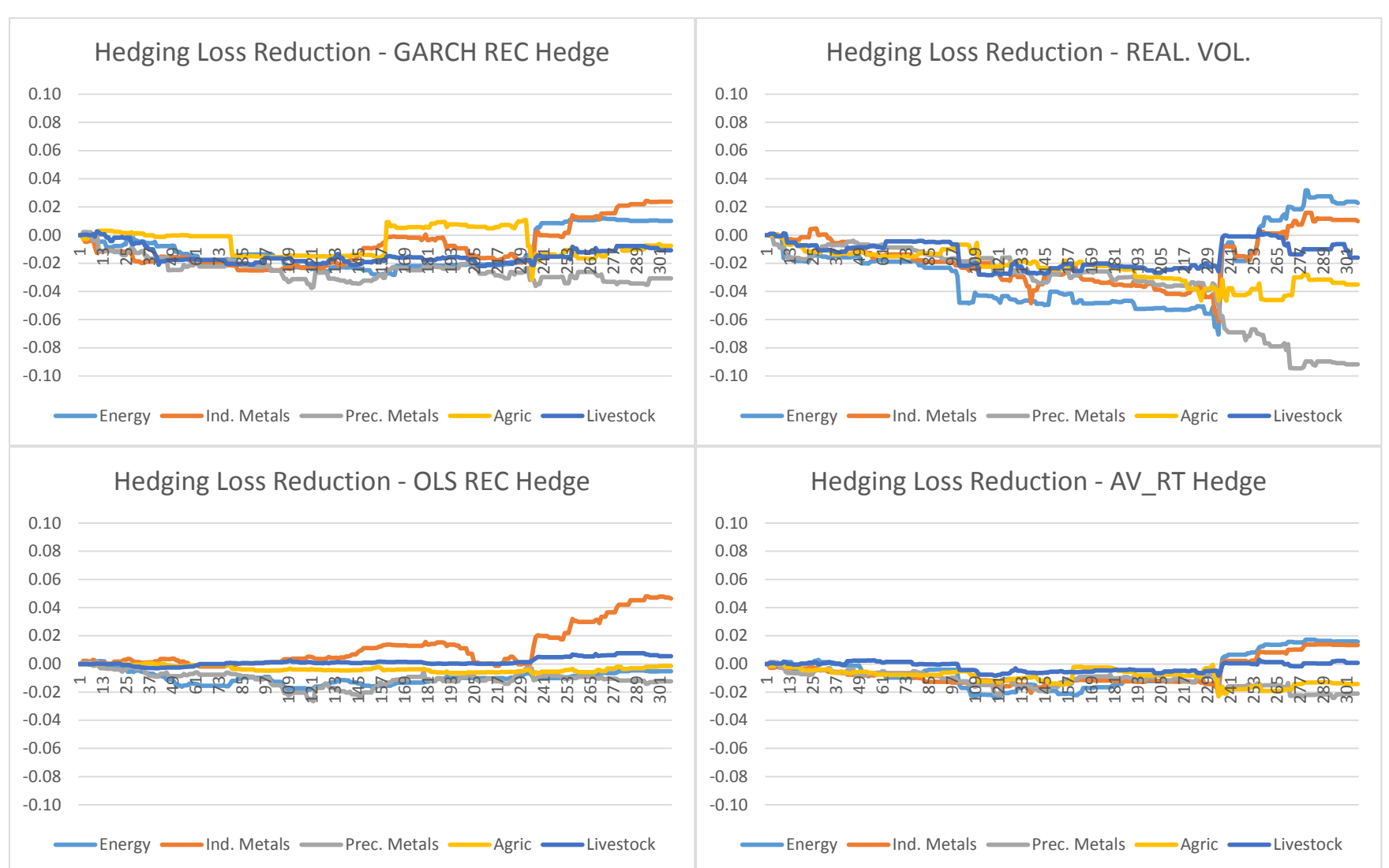

Notes: This figure depicts time-variation in the out-of-sample ability of a commodities hedge for the equity index to reduce semi-variance using four different methods to estimate the hedge ratio. These are: i) recursive GARCH method (GARCH REC), ii) realized volatility from the last 21 trading days (REAL. VOL.), iii) recursive OLS (OLS REC) and iv) a simple average of methods i) through iii) denoted (AV_RT). For GARCH REC and OLS REC a start-up period of 60 observations is used (which then expands as time progresses).

The sum of losses metric calculated in all graphs is: $\frac{\sum_{t=1}^{T} R_{U, t}^{-}-\sum_{t=1}^{T} R_{H, t}^{-}}{\sum_{t=1}^{T} R_{U, t}^{-}}$

$R_{U, t}^{-}$is the return to the unhedged portfolio, which has a weight of 1 in the S\&P 500, when the portfolio return is negative and zero otherwise. $R_{H}$ is the return to the hedged portfolio; this has a weight of 1 in the S\&P 500 and weight of $-\mathrm{H}$ in commodity, where $\mathrm{H}$ is the hedge ratio. This is basically the cumulative reduction in losses so far to period t, divided by the full sample sum of losses. A positive value here indicates the hedge has reduced losses. An increase in this measure at period t indicates that the hedge reduced variance in period t. So in the final graph this tells us that using the AV_RT method, the hedge using industrial metals reduces portfolio losses by about $2 \%$ over the full-sample. 


\section{FIGURE 9: IMPACT ON PORTFOLIO RETURNS.}

Impact on Portfolio Returns - GARCH REC

$$
\text { hedge }
$$

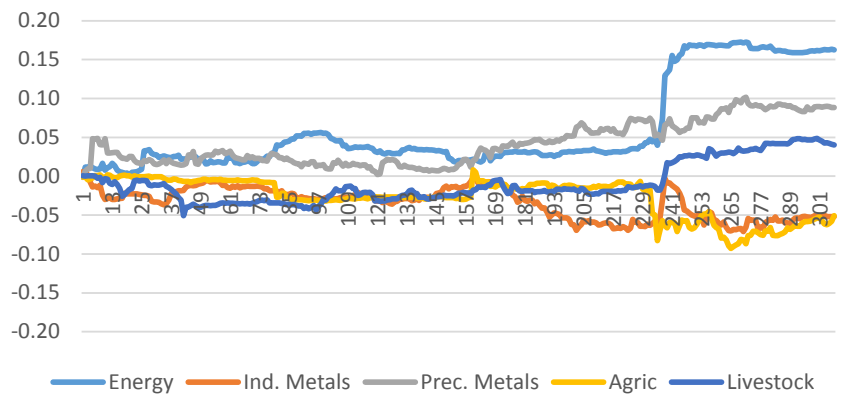

Impact on Portfolio Returns - OLS REC Hedge

0.20

0.15

0.05

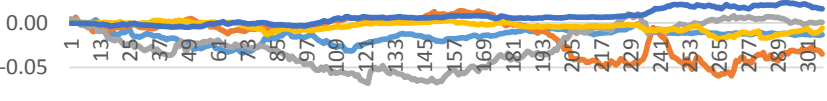

$-0.10$

$-0.15$

$-0.20$

Energy —Ind. Metals —Prec. Metals —Agric —Livestock
Impact on Portfolio Returns - REAL. VOL.

$$
\text { hedge }
$$

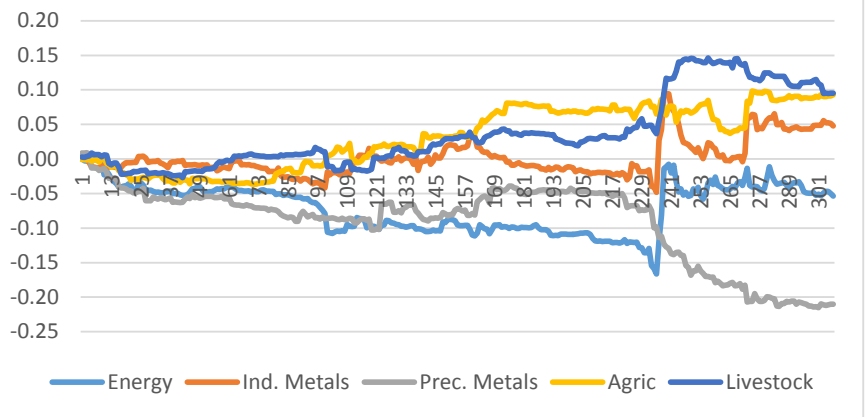

Impact on Portfolio Returns - AV_RT Hedge

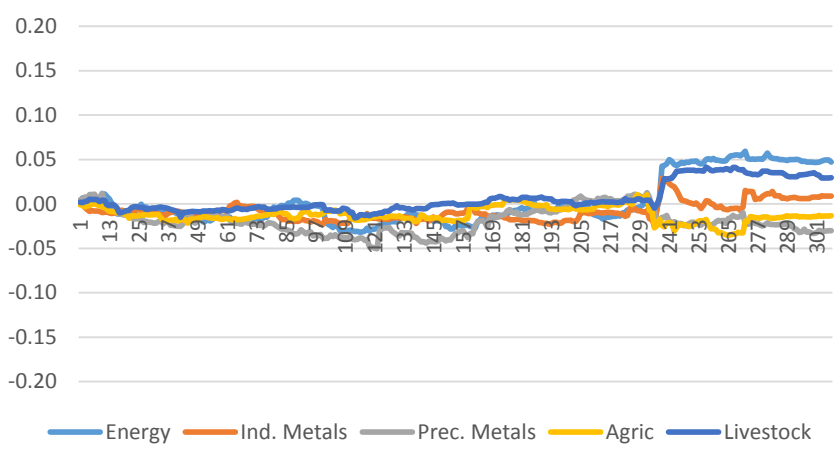

Notes: This figure depicts time-variation in the out-of-sample ability of a commodities hedge for the equity index to reduce semi-variance using four different methods to estimate the hedge ratio. These are: i) recursive GARCH method (GARCH REC), ii) realized volatility from the last 21 trading days (REAL. VOL.), iii) recursive OLS (OLS REC) and iv) a simple average of methods i) through iii) denoted (AV_RT). For GARCH REC and OLS REC a start-up period of 60 observations is used (which then expands as time progresses).

The hedging effectiveness metric calculated in all graphs is: $\frac{\sum_{t=1}^{T} R_{H, t}-\sum_{t=1}^{T} R_{U, t}}{\sum_{t=1}^{T} R_{U, t}}$

$R_{U}$ is the return to the unhedged portfolio, which has a weight of 1 in the S\&P $500 . R_{H}$ is the return to the hedged portfolio; this has a weight of 1 in the S\&P 500 and weight of $-\mathrm{H}$ in commodity, where $\mathrm{H}$ is the hedge ratio. This is basically the cumulative gain in return so far to period t, divided by the full sample unhedged portfolio return. A positive value here indicates the hedge has increased portfolio return. An increase in this measure at period t indicates that the hedge increased return in period t. So in the final graph this tells us that using the AV RT method, the hedge using energy increases portfolio return by about $5 \%$ over the fullsample. 